\title{
Black Tea Source, Production, and Consumption: Assessment of Health Risks of Fluoride Intake in New Zealand
}

\author{
Declan T. Waugh, ${ }^{1}$ Michael Godfrey, ${ }^{2}$ Hardy Limeback, ${ }^{3}$ and William Potter ${ }^{4}$ \\ ${ }^{1}$ EnviroManagement Services, 11 Riverview, Dohertys Rd, Bandon, Co. Cork P72 YF10, Ireland \\ ${ }^{2}$ Bay of Plenty Environmental Health Clinic, 1416A Cameron Road, Tauranga 3012, New Zealand \\ ${ }^{3}$ Faculty of Dentistry, University of Toronto, 124 Edward Street, Toronto, ON, Canada M5G 1G6 \\ ${ }^{4}$ Department of Chemistry and Biochemistry, KEH M2225, University of Tulsa, Tulsa, OK, USA \\ Correspondence should be addressed to Declan T. Waugh; declan@enviro.ie
}

Received 23 December 2016; Revised 25 April 2017; Accepted 18 May 2017; Published 21 June 2017

Academic Editor: Pam R. Factor-Litvak

Copyright ( 2017 Declan T. Waugh et al. This is an open access article distributed under the Creative Commons Attribution License, which permits unrestricted use, distribution, and reproduction in any medium, provided the original work is properly cited.

In countries with fluoridation of public water, it is imperative to determine other dietary sources of fluoride intake to reduce the public health risk of chronic exposure. New Zealand has one of the highest per capita consumption rates of black tea internationally and is one of the few countries to artificially fluoridate public water; yet no information is available to consumers on the fluoride levels in tea products. In this study, we determined the contribution of black tea as a source of dietary fluoride intake by measuring the fluoride content in 18 brands of commercially available products in New Zealand. Fluoride concentrations were measured by potentiometric method with a fluoride ion-selective electrode and the contribution of black tea to Adequate Intake (AI) and Tolerable Upper Intake Level (UL) was calculated for a range of consumption scenarios. We examined factors that influence the fluoride content in manufactured tea and tea infusions, as well as temporal changes in fluoride exposure from black tea. We review the international evidence regarding chronic fluoride intake and its association with chronic pain, arthritic disease, and musculoskeletal disorders and provide insights into possible association between fluoride intake and the high prevalence of these disorders in New Zealand.

\section{Introduction}

Internationally, New Zealand (NZ) is one of the highest black tea per capita consumption countries [1]; yet no information is available to consumers on the fluoride (F) levels in black tea products in NZ. It is now recognized that, of all the common foodstuffs, tea produced from the leaves of Camellia sinensis has one of the greatest potentials for increasing the daily fluoride (F) intake [2-10]. Tea has long been considered as a useful natural source of $\mathrm{F}$ for the prevention of dental caries [11-16] and its anticariogenic effect has been widely demonstrated in a number of human studies [17-23]. Indeed, Onisi et al. (1978) suggested that a solution to the psychological, political, and ethical obstacles to water fluoridation and the use chemical fluorides was recommending tea consumption [24]. Moreover, Onisi et al. (1981) found that drinking a cup of tea daily with a fluoride content of $0.48 \mathrm{mg}$ was more protective of oral health than water fluoridation [19]. A recent large-scale observational study conducted in the United States of America (USA) and England which examined the oral health of adults aged 25 years and over found that mean number of missing teeth was significantly higher in the US than in England [25]. Considering that over 70\% of the USA population and $<10 \%$ of the UK population are provided with fluoridated drinking water, this would appear to suggest that tea consumption is better than water fluoridation for oral health. However, it should be noted that most of the reports suggest that the anticaries effect observed with tea is due primarily to the antibacterial properties of the organic components (polyphenols and tannins) rather than the cariostatic effect of $F[19,26,27]$.

The earliest reports identifying tea as a hyperaccumulator of $\mathrm{F}$ appear to be those published in the 1930s [28, 29], approximately a decade before the time when fluoridation of public water was initiated in the USA. In 1954, dental researchers cautioned that while fluoridation of communal 
water supplies was expanding rapidly in the USA in consideration of fluoridation in the UK, it should be recognized that Britons already take in appreciable amounts of $\mathrm{F}$ from drinking tea [10]. Early studies by Jackson and Weidmann (1958) reported that tea was a significant contributor to bone $\mathrm{F}$ levels in humans. Even in the absence of $\mathrm{F}$ in water, there was at least a tenfold increase in bone $\mathrm{F}$ levels over time, which was attributed to black tea consumption in England [30]. Similarly, in the Persian Gulf, early studies by Azar et al. (1961) observed that habitual and excessive tea drinking may exaggerate the manifestation of fluorosis [31]. Many individuals drink tea rather than water as their primary means of fluid intake $[32,33]$. Most people drink tea as an infusion (adding hot or boiling water); however, in some countries, including India, China, and Egypt, tea is drunk as a decoction (tea and water are boiled together) [34].

It is reported that tea leaves contain $98 \%$ of the $\mathrm{F}$ of the whole plant [35], with the most accumulated in old leaves [36]. Most of the fluorine accumulated in the leaves is in the form of the F anion [37]. The four types of tea most commonly found in the market are black tea (BT), green tea (GT), oolong tea, and white tea. The difference among them lies in the different processing or, in the case of white tea, different harvesting times. White tea leaves are picked and harvested before they fully open; this is done when the buds are still covered by fine white hair. In the case of white tea and GT, the leaves are steamed quickly (Japanese style) or roasted in pans with dry heat (Chinese type) after harvesting to prevent oxidation of polyphenols. Prior to final drying, the leaves are pressed and rolled, developing their characteristic shape and sizes. After drying, the leaves are sorted into various grades. In the production of BT, the leaves are oxidized (also called "fermentation") before drying and grading. To accelerate the oxidation process, the leaf size is reduced by rupturing the withered tea leaf using "orthodox rollers" or "crush-tear-curl" (CTC) machines. BT produced using rollers is more suitable for large-leaf-type tea (orthodox), whereas CTC method leads to obtaining small particles suitable for teabags (fanning and dust). Broadly, BT is categorized as either orthodox or CTC. Oolong tea, which is manufactured mainly in Taiwan, is produced with a shorter fermentation period than black tea and is said to have a taste and colour somewhere between GT and BT [38-41]. Tea is generally exported with minimal processing to importing consumer countries, where it is blended and packaged by the tea companies [42]. Generally, unblended black teas are named after the region in which they are produced, such as Ceylon or Assam tea, while blended teas include a variety of teas, often from countries of different origin. The two tea products most widely consumed are GT which is primarily consumed in Southeast Asia and BT which is the main tea beverage in India, Europe, Russia, North America, the Middle East, Indonesia, North Africa, Chile, Hong Kong, Australia, and New Zealand. BT represents over $90 \%$ of all tea sold in the West [1]. The consumption of oolong tea is mostly restricted to China and Taiwan [43].

There are two main varieties of Camellia sinensis that make up most of the tea consumed internationally, Camellia sinensis var. assamica, or the broad-leaf variety of the tea plant, and Camellia sinensis var. sinensis, or the small-leaf variety of the tea plant $[44,45]$. GT is most often sourced from the small-leaf variety because it has a sweeter taste than the broad-leaf variety that is usually used for BT production. Tea plants of the broad-leaf variety are quickly growing plants or either tree or bush form, suitable for warm, tropical, and subtropical environments and are predominately grown in Southwest China, Northern Laos, Northern Vietnam, Myanmar, Cambodia, North Eastern India, and Africa. The smallleaf variety is more suitable for colder, temperate climates and is predominately grown in eastern China, Taiwan, Japan, India's Darjeeling, and tea growing countries outside of Asia [46, 47].

Although tea is the most popular beverage consumed by two-thirds of the world's population [48], the consumption of tea remains much less in most of the Americas, tropical Africa, and Nordic, Baltic, and Southern European countries $[1,49]$. While consumption of tea in the USA is among the lowest in the world [1], the USA is unique for its large consumption of iced tea, prepared at home or sold as canned or bottled beverages. According to the Tea Association of the USA the canned/bottled tea segment comprised just under $50 \%$ of the market share in 2016 , with bagged/loose leaf tea comprising approximately $23 \%$ market share [50]. Iced tea is prepared by cooling traditionally brewed BT, but it is sometimes prepared by the prolonged steeping of tea at room temperature or in chilled water. Cold water-soluble instant teas are also used [38]. Instant tea is a powder that water is added to, in order to be reconstituted into a cup of tea, and is produced from the fermented juice of BT leaves through hot water extraction, aroma recovery, soluble solids concentration, aroma restoration, and drying to obtain concentrate tea granules [51].

BT consumption is the staple of the Australian and NZ diet since both countries were colonized by British settlers. Notably, by the mid-nineteenth century, colonial Australians were using between four and five kilograms of tea per capita annually, the highest consumption of tea per capita globally [52]. By the beginning of the twentieth century, NZ had the second highest annual per capita consumption of tea in the world $(3.0 \mathrm{~kg}$ ) next to Australia (3.1 kg) [49]. Indeed annual per capita tea consumption was 75 -fold higher than India $(0.04 \mathrm{~kg}), 15$-fold higher than Japan $(0.2 \mathrm{~kg}), 10$-fold higher than France, and 7.5-fold higher than the USA (0.4 kg) [49].

Paradoxically, during the 1960s when water fluoridation was actively expanding in NZ, annual per capita tea consumption of tea was even higher at $3.35 \mathrm{~kg}$ per person per year [53]. Despite the recent decline in per capita consumption of tea, BT remains one of the most frequently consumed beverages in NZ consumed by 80 percent of adult New Zealanders aged 22 to 55 years [54]. In 2012, per capita consumption of BT per person per year was reported to be 8 -fold higher in $\mathrm{NZ}$ compared to the USA [1]. Per capita consumption in Australia was 5-6-fold higher than the USA [1]. The differences in per capita consumption are reflected in population based case control studies conducted in Australia and the USA. For example, Nagle et al. (2010) reported that 60\% of Australian women aged $18-70+$ years consume 1 to 4 or more cups per day [55]. In comparison, Song et al. (2008) reported that 
the frequency of women aged 35-74 years in the USA who drank one or more cups of BT per day was 10 per cent [56]. Similarly, the 2008 Food Standards Australia NZ Total Diet Survey (TDS) identified that for Australian adults aged 30-69 years mean daily consumption of tea was approximately $1 \mathrm{~L}$ [33]. At the same time the USA National Health and Nutrition Examination Survey (2007/2008) reported that the mean daily consumption of tea among adult non-Hispanic whites age 20 years and over was $236 \mathrm{ml}$ per day [57].

In their review of $\mathrm{F}$ in drinking water released in March 2006, the National Research Council (NRC) of the USA National Academies of Science (NAS) recommended that the USA Environmental Protection Agency (EPA) updates its F risk assessment to include new data on health risks and better estimates of total exposure $[2,58]$. The NRC identified subpopulations that might be particularly susceptible to the effects of $\mathrm{F}$ including people with high activity levels (e.g., athletes, workers with physically demanding duties, and military personnel); pregnant or lactating women; individuals with renal disease, because of their high fluid intakes and compromised ability to excrete $\mathrm{F}$ which can result in greater accumulation of $\mathrm{F}$ in their bodies; the elderly, because of their long-term accumulation of $\mathrm{F}$ into their bones; and individuals with medical conditions that can make people more susceptible to the effects of $\mathrm{F}$, such as individuals with thyroid disorders or individuals with compromised immune systems [2].

The NRC recommended a wide range of additional epidemiology, toxicology, clinical medicine, environmental exposure, and biomonitoring assessments that need to be undertaken in order to fill data gaps. Further studies were recommended in identifying sources of $\mathrm{F}$ and determining bone, soft tissue, plasma, and urinary F levels and further studies to clarify the relationship between $\mathrm{F}$ intake, fluoride concentration in bone, clinical symptoms of skeletal fluorosis, and other factors that may influence the risk of bone fractures [2]. The NRC also recommended that carefully conducted studies of exposure to $\mathrm{F}$ and emerging health parameters of interest (e.g., endocrine effects and brain function) should be performed in populations exposed to various concentrations of F. Further studies were recommended to investigate the effects of $\mathrm{F}$ on brain, kidney, liver, and immune system function as well as in vivo human genotoxicity studies in US populations or other populations with nutritional and sociodemographic variables similar to those in the United States. Additional studies were also recommended to investigate the association between $\mathrm{F}$ intake and thyroid disease, calcium metabolism, pineal function, and development of glucose intolerance and diabetes [2].

In the USA, fluoridation of community drinking water for prevention of dental caries commenced in 1945, reaching 3 per cent of the population by 1951 and 74.6 per cent in $2012[59,60]$. When water fluoridation commenced in the USA, drinking water was considered the main dietary source of $\mathrm{F}$ intake for the population. Today, community water fluoridation and $\mathrm{F}$ toothpaste are considered the most common sources of $\mathrm{F}$ exposure in the USA [61]. In 2010, an exposure assessment conducted by the EPA concluded that the use of fluoridated water for commercial beverage production and the increase of $\mathrm{F}$ in solid foods because of fluoridated commercial process have likely resulted in increased dietary $\mathrm{F}$ intake adding to the risk for overexposure [62]. In dietary exposure assessments, uncertainty results from limitations in scientific knowledge, including the factors that determine exposure, and data availability [63]. Risk assessments can address such questions as to whether a risk to health will be reduced if certain actions are taken and, if so, by what magnitude and whether new risks might be introduced when such actions are taken [64]. However, risks cannot be reliably estimated if exposures and their uncertainties are not properly characterized and sufficiently quantified [64]. Recently, due to potential concerns associated with cumulative $\mathrm{F}$ exposure and to ensure a high level of consumer protection, the USA Public Health Service (PHS) finalized a recommendation for lowering the levels of water fluoridation programs to $0.7 \mathrm{mg} / \mathrm{L}$ for the whole USA $[65,66]$. The earlier PHS recommendation for $\mathrm{F}$ concentrations was based on outdoor air temperature of geographic areas and ranged within $0.7-1.2 \mathrm{mg} / \mathrm{L}$. However, fewer than $1 \%$ of fluoridated systems in the USA used a F concentration of $0.7 \mathrm{mg} / \mathrm{L}$. Implementation of the new recommendation is expected to lead to a reduction of approximately $25 \%$ in $\mathrm{F}$ intake from drinking water alone and a reduction of approximately $14 \%$ (range 5\%-29\%) in total $\mathrm{F}$ intake [66].

In NZ, the USA PHS endorsement of water fluoridation in 1951 generated consequences, laying the foundation for implementation of water fluoridation in the first community outside of North America, when Hasting Borough Council implemented fluoridation in 1953 [67]. However, in contrast to the USA, Harrison (1949) identified that BT consumption was the major dietary source of $\mathrm{F}$ among New Zealanders [68]. Subsequently, in 1957, the report of the NZ Commission of Inquiry appointed to inquire into and report upon fluoridation endorsed the fluoridation of municipal water supplies [69]. However, the contribution of tea to dietary F intake was not considered. Following publication of this report, fluoridation rapidly expanded in the 1960s extending to Lower Hutt, Palmerston North (1962), Wellington (1965), Auckland (1966), Hamilton (1966), Dunedin (1967), and New Plymouth (1971) [70]. The Drinking-Water Standards for NZ (2008) include a maximum acceptable value (MAV) for $F$ of $1.5 \mathrm{mg} / \mathrm{L}$ and recommended a target $\mathrm{F}$ range of $0.7-1.0 \mathrm{mg} / \mathrm{L}$ for oral health reasons [71]. Actual $\mathrm{F}$ concentrations in municipal water in NZ have been found to average about $0.8-0.9 \mathrm{mg} / \mathrm{L}$ in fluoridated areas and around $0.15 \mathrm{mg} / \mathrm{L}$ in nonfluoridated areas [72]. At present, there are some 84 water supplies in the NZ where $\mathrm{F}$ is intentionally added [69], providing fluoridated drinking water to a little over half of the NZ population [73]. Colquhoun (1987) examined child dental health differences based on fluoridation status and demographic factors in NZ and found that when similar populations were compared, there was no obvious dental health benefits related to fluoridation [74]. More recently, the 2015 NZ Health Department statistics on 46,948 five- and 46,942 eight-year-old children revealed a $0.89 \%$ caries-free difference at 5 and $1.27 \%$ at 8 years, respectively, between fluoridated and nonfluoridated communities [75]. 
In 2015, the NZ Government started the legislative process to remove decision-making on fluoridation away from local authorities which will make fluoridation a legal requirement for local authorities if directed by the district health boards [76]. If these legislative changes are implemented, the percentage of the NZ population provided with fluoridated water will significantly increase. This will result in increases in cumulative $\mathrm{F}$ intake and may increase the risk of chronic fluoride exposure, particularly among tea drinkers. The NRC (2006) reported that, due to the substantial amounts of $F$ in commercial tea brands, a combination of exposures can lead to higher than expected $\mathrm{F}$ intake, which may contribute to musculoskeletal problems [2]. As the borderline between toxic and beneficial intake as regards the prevention of dental caries is very narrow, the average daily $\mathrm{F}$ intake of a community must be investigated well in order to estimate whether or not there is reason to add $\mathrm{F}$ to the drinking water and, if so, what is the safe but adequate concentration [77].

Cressey (2010) found that NZ infants fully formulafed on formulae prepared with optimally fluoridated water (0.7-1.0 mg/L) exceeded the upper level of intake (UL) for F and are at increased risk of dental fluorosis [78]. Previously, Colquhoun (1984) reported a highly significant difference between the incidence of dental fluorosis among children living in fluoridated and nonfluoridated areas of NZ [79]. The prevalence of dental fluorosis in fluoridated communities was $24.9 \%$, ranging from 22.7 to $27.7 \%$ depending on socioeconomic factors, with the highest prevalence found among children from lower socioeconomic areas. In comparison, the prevalence of dental fluorosis in nonfluoridated communities where the drinking water source was groundwater was $4.9 \%$ and $2.9 \%$ in nonfluoridated communities where drinking water source was rainwater. Notably, among the children examined in the nonfluoridated area, the most advanced case of dental fluorosis was a 10-year-old Maori male, due to consumption of tea from an early age [79]. Mackay and Thomson in a 2005 study of 436, 9-10-year-old, children in Southland, New Zealand, found that among children continuously residing in a fluoridated area up to the age of 4 years $32.1 \%$ had diffuse opacities, consistent with dental fluorosis, compared to $19.0 \%$ for children with no or noncontinuous residence in a fluoridated area [80]. More recently, the 2009 Oral Health Survey reported that, using Dean's Index of Fluorosis, $44.5 \%$ of 8 -30-year-olds had some degree of dental fluorosis [81]. This data illustrates that the prevalence of dental fluorosis in NZ has increased significantly since the 1980s. These findings raise other implications as chronic exposure to $\mathrm{F}$ in infancy will result in accumulation of $\mathrm{F}$ in skeletal tissue. Thus, as people age, their bone F levels will be higher than for similar aged individuals residing in nonfluoridated communities.

In addition to tea and fluoridated water, other sources of $\mathrm{F}$ exposure include other beverages produced from fluoridated water (beers, coffee, soft drinks, and fruit juices); pesticide residues in foods, foods processed or cooked in fluoridated water; foods grown in soil containing $\mathrm{F}$ or irrigated with fluoridated water; consumption of foods with elevated $\mathrm{F}$ levels (i.e., seafood and processed chicken); foods cooked in Teflon cookware; tobacco consumption; use of fluoridated toothpaste; fluoridated mouthwash; use of medical inhalers containing fluoridated gases, and fluoridated medications, in addition to other environmental or occupational exposures to $\mathrm{F}$.

Typical fluoridated medications that have been found to contribute to fluoride burden include fluoroquinolone antibiotics [82]; the antifungal medication voriconazole [83]; the antimetabolite drug fluorouracil [84]; the antiarrhythmic drug flecainide [85]; anti-inflammatory drugs diclofenac, niflumic acid, flufenamic, and antrafenine [86, 87]; the antimalarial drug 5-fluoro-amodiaquine [88]; antipsychotic medications such as haloperidol [89]. There is evidence to suggest that Teflon products may significantly alter the $\mathrm{F}$ uptake in prepared foods [90]. There is additional evidence that consumption of beer and wine can contribute significantly to $\mathrm{F}$ intake, particularly among habitual users $[91,92]$. Evidence suggests that smokers will be exposed to higher chronic exposure to fluoride than nonsmokers [9397]. Recently, Gondal et al. (2015) reported that the fluoride content in four different brands of cigarettes commercially available in Saudi Arabia ranged from 233.9 to $360.2 \mathrm{ppm}$ [98]. However, due to limited awareness on the fluoride level in tobacco, it is usually ignored when calculating the total dietary intake of fluoride [98].

Regarding food production, it is noteworthy that NZ agricultural soils are already exceeding the thresholds protective against chronic fluorosis in grazing animals, due to large-scale use of phosphatic fertilizers rendering large areas of agricultural lands unsuitable for particular types of primary production [99]. Accumulation of $F$ in soils has implications for not only grazing animals but also soil microbial activity and fertility [99-102], soil acidification [103], and the potential for increased dietary intake from cereals and vegetables $[104,105]$.

The relationship between $\mathrm{F}$ accumulation in agricultural soils from large-scale application of phosphate fertilizers is a relatively new phenomenon [99] and has many parallels to water fluoridation. Both progressed in the second half of the 20th Century and the consequences of long-term accumulation have largely gone undocumented. Indeed, water fluoridation provided an opportunity for the fertilizer industry to dispose of otherwise hazardous industrial waste products by reusing these materials for the purposes of water fluoridation. In doing so waste became a valuable commodity. Because $\mathrm{F}$ does not biodegrade, the contribution from fertilizer inputs, industrial and environmental emissions accumulate in the environment. Treated wastewater and sewage sludge from water treatment plants treating fluoridated wastewaters also contain F, which ultimately adds to the environmental burden on ecosystems. The use of fertilizers and fluoridated chemicals in tea production has also increased in the last half century to meet the challenges of increased yield and the management of tea pests associated with monoculture production. This has led to concerns regarding pesticide residues in tea products and its toxic hazards to consumers [106]. Regulatory agencies have recently fixed the maximum residue levels and/or permissible limits of pesticides/chemicals in teas [107], and chemical characteristics have been defined by the International Organization for Standardization (ISO) 
TABLE 1: Tea brands, weight of teabag, and fluoride content in tea infusions.

\begin{tabular}{|c|c|c|c|c|}
\hline $\begin{array}{l}\text { Sample } \\
\text { number }\end{array}$ & Brand name & $\begin{array}{l}\text { Weight of tea } \\
\text { bag }(g)\end{array}$ & $\begin{array}{c}\text { Fluoride in tea infusions made } \\
\text { with } 0.7 \mathrm{mg} / \mathrm{L} \text { fluoridated } \\
\text { drinking water }(\mathrm{mg} / \mathrm{L})\end{array}$ & $\begin{array}{l}\text { Fluoride in tea infusion made } \\
\text { with deionized water }(\mathrm{mg} / \mathrm{L})\end{array}$ \\
\hline 1 & Bell Kenya Bold & 3.3 & 3.9 & 3.2 \\
\hline 2 & Bell Original Tea & 2.3 & 3.4 & 2.7 \\
\hline 3 & Pams-New World Supermarket Tea & 2.4 & 3.1 & 2.4 \\
\hline 4 & Pak-n-Save Supermarket Budget Tea & 2.1 & 2.8 & 2.2 \\
\hline 5 & Choysa Extra Strong & 2.3 & 2.7 & 1.9 \\
\hline 6 & Twinings English Breakfast Extra Strong & 2.7 & 2.6 & 1.8 \\
\hline 7 & Choysa Classic & 2.2 & 1.8 & 1.3 \\
\hline 8 & Twinings Classic English Breakfast & 2.3 & 1.7 & 1.1 \\
\hline 9 & Woolworths Home Brand Tea & 1.9 & 1.6 & 0.9 \\
\hline 10 & Dilmah Organic & 2.3 & 1.5 & 0.8 \\
\hline 11 & Chanui Pure Ceylon Tea & 2.2 & 1.4 & 0.8 \\
\hline 12 & Twinings Lapsang Souchong Tea & 2.3 & 1.4 & 0.8 \\
\hline 13 & Planet Organic Tea & 2.2 & 1.2 & 0.7 \\
\hline 14 & Dilmah Premium Ceylon & 1.7 & 1.2 & 0.6 \\
\hline 15 & Chanui Irish Breakfast & 2.3 & 1.1 & 0.5 \\
\hline 16 & Dilmah English Breakfast Tea & 2.0 & 1.1 & 0.5 \\
\hline 17 & Chanui English Breakfast & 2.2 & 0.9 & 0.4 \\
\hline 18 & Dilmah Earl Grey Tea & 2.2 & 0.9 & 0.4 \\
\hline
\end{tabular}

Note. Two teabags selected at random from each branded box of tea. Each tea bag was brewed for a period of 5 minutes with $200 \mathrm{~mL}$ of water initially at $100^{\circ} \mathrm{C}$. After five minutes of extraction, teabags were removed and the infusions were cooled to room temperature $\left(18-20^{\circ} \mathrm{C}\right)$. F level of boiled and cooled tap water $0.7 \mathrm{mg} / \mathrm{L}$. F level of deionized water was $0.0 \mathrm{mg} / \mathrm{L}$. The F content of tea infusions made with drinking water is the mean of two samples tested from each brand of tea.

for BT and GT $[108,109]$. However, there is no requirement currently to measure the $\mathrm{F}$ level in tea, and no maximum residue levels (MRLs) have been established for F levels in tea products.

Thus, in order to make safety evaluations, it is necessary to determine the $\mathrm{F}$ content of various products of black tea available to consumers [5]. A recent review of the health effects of water fluoridation in NZ reported that individual exposure due to the consumption of tea can range from 0.04 to $2.7 \mathrm{mg} /$ day [110]. Unfortunately, the information base on which to estimate exposures and doses associated with tea consumption in NZ is completely lacking. Moreover, the suggested upper limit is significantly lower than that reported in scientific literature internationally [5-10].

Therefore, the aim of our study is to determine the $\mathrm{F}$ levels in the most widely available and consumed tea beverages in NZ, thereby improving the status of scientific knowledge and the treatment of uncertainty in dietary risk assessments for $\mathrm{F}$ intake. The study further aims to access the range of likely human exposures to $\mathrm{F}$ from $\mathrm{BT}$ consumption in NZ, while also reviewing the factors that influence the $\mathrm{F}$ content in tea products and infusions. In addition, the study will look at temporal changes in $\mathrm{F}$ exposure from tea and address bioavailability of $\mathrm{F}$ from tea. In this paper, we provide an overview of the international literature on the relationship between $\mathrm{F}$ intake, chronic pain, musculoskeletal disorders, and arthritic diseases and discuss its relevance to NZ.

\section{Materials and Methods}

All 18 tea products employed in the study were procured as boxes of teabags from supermarkets, retail outlets, and health food stores between July and August 2016. The samples represent the clear majority of BT products purchased or available to $\mathrm{NZ}$ consumers. We did not consider other types, such as ready to drink bottled or canned iced tea, green, oolong, white, yellow, or herbal tea, which are not widely consumed in NZ. The characteristics of the analysed teas are listed in Table 1. The samples were prepared as per our previous study for measuring $\mathrm{F}$ content in black tea products in the Republic of Ireland [10]. Briefly, prior to analysis duplicate teabags were randomly selected from each packaged tea product, weighted, and placed in a porcelain cup. Municipal fluoridated tap water was boiled in an electric kettle, and approximately $200 \mathrm{~mL}$ of water was poured into the cup and a single teabag allowed too steep unagitated for a period of 5 minutes (according to the tea industry's recommended brew time). It is observed that the temperature decreased from 100 to $70^{\circ} \mathrm{C}$ during the first five minutes. After five minutes, the teabag was extracted and the infusion was allowed to cool to room temperature. The scenario was repeated in for each brand of tea tested. Controls were prepared by using boiled deionized water, such that 54 samples were collected in total. The F determinations were conducted potentiometrically after addition of total ionic strength adjustment buffer (TISAB) using a $\mathrm{F}$ ionselective electrode (Extech FL700) [10]. The Extech FL700 
has a reported resolution of $0.1 \mathrm{mg} / \mathrm{L}$ and overall accuracy of $\pm 3 \%$. The TISAB buffer tablet was supplied by Extech (FL704 TISAB tablets) and added to a $20 \mathrm{ml}$ aliquot of tea infusion placed in a polyethylene plastic sample container prior to measurement. A series of $\mathrm{F}$ standards was prepared by using a $100 \mathrm{mg} / \mathrm{L}$ F Eutech standard solution (Eutech Instruments, F Standard Solution Code number ECSCSFL3BT) by diluting appropriate volumes to $100 \mathrm{ml}$ with deionized water. Then, the electrode was calibrated to concentrations of $0.0,0.5$, $1.0,5.0$, and $10.0 \mathrm{mg} / \mathrm{L}$. Prior to sampling and at the end of each group of five samples, the electrode was rechecked for accuracy.

The results of these analyses are presented in Table 1. For the duplicate tea infusion samples, the mean value is provided. The variability between duplicate samples was very small, generally within $0.1 \mathrm{mg} / \mathrm{L}$ and is therefore not reported.

\section{Results}

For the purposes of examining $\mathrm{F}$ intake from tea infusions, it is the F content in infusions prepared with tap water that is of interest. When prepared with tap water, the F concentration in tea infusions ranged from 0.9 to $3.9 \mathrm{mg} / \mathrm{L}$ with a mean of $1.9 \mathrm{mg} / \mathrm{L}$. Significant differences in F concentrations were observed between tea brands, with NZ economy and NZ own brand supermarket blended tea products having the highest $\mathrm{F}$ concentrations. Variations were also observed in the weight of teabags, which were found to range from $1.7 \mathrm{~g}$ to $3.3 \mathrm{~g}$. Notably, the highest F concentration in tea infusions $(3.9 \mathrm{mg} / \mathrm{L})$ was found in the product with the maximum weight of tea (Bell Kenyan Bold). Notwithstanding this, the second highest concentration $(3.4 \mathrm{mg} / \mathrm{L})$ was also found in Bell Original Tea where the weight of tea was comparable to other tea products tested.

It is important to note that Bell teas have the largest market share in NZ [111], representing the main brand of choice among consumers [54]. Consequently, these products would be most representative of consumer exposure. Notably, the $\mathrm{F}$ content in tea infusion made from these products is 3-4 times higher than the accepted level in drinking water in NZ. Variations were also observed in the F concentrations of tea infusions based on country of origin with the highest levels found in teas originating from Kenya and the lowest in teas originating from Sri Lanka. However, none of the products provided information on the F content.

Overall, the present study found that the $\mathrm{F}$ ion concentration in tea infusions prepared from 18 different black teabag commodities exceeded the new USA DHHS recommendation for a single level of $0.7 \mathrm{mg}$ of $\mathrm{F}$ per litre of water [66]. In addition, sixteen products ( 89 per cent) exceeded the upper range permitted for fluoridated drinking water in $\mathrm{NZ}(1.0 \mathrm{mg} / \mathrm{L})$ and nine products $(50 \%)$ exceeded the World Health Organization (WHO) maximum permissible limit for $\mathrm{F}$ in drinking water $(1.5 \mathrm{mg} / \mathrm{L})$.

While there are no internationally safety standards for the $\mathrm{F}$ content in tea beverages, $55 \%$ of the tea infusions exceeded the permissible level in the US for imported bottled water $(1.4 \mathrm{mg} / \mathrm{L})$ [112] and $50 \%$ exceeded the maximum permitted level requiring labelling and safety precautions for bottled mineral water under European regulations $(1.5 \mathrm{mg} / \mathrm{L})$ [113].

In NZ, Foods Standards Australia New Zealand has established a maximum level (ML) of $1.0 \mathrm{mg} / \mathrm{L}$ (naturally occurring and added) for packaged potable water [114]. Based on this recommendation, $90 \%$ of the teas tested would exceed this $\mathrm{ML}$ when prepared with tap water containing $0.7 \mathrm{mg} / \mathrm{L}$. Moreover, all of the tea products would exceed this ML when tap water contains more than $0.7 \mathrm{mg} / \mathrm{L}$. As expected, the use of fluoridated tap water at $0.7 \mathrm{mg} / \mathrm{L}$ was found to significantly increase the measured $\mathrm{F}$ content in all tea infusions. In NZ, the Ministry of Health recommends the adjustment of $\mathrm{F}$ to between 0.7 and $1.0 \mathrm{mg} / \mathrm{L}$ in drinking water [71]; thus, the value of $0.7 \mathrm{mg} / \mathrm{L}$ in this study represents the lower range found in fluoridated drinking water in NZ.

Notwithstanding the contribution of fluoridated water, when prepared with deionized water, the F concentration was less than $0.5 \mathrm{mg} / \mathrm{L}$ in 2 out of 18 samples of the tea infusions, $0.5-1.0 \mathrm{mg} / \mathrm{L}$ in 5 out of 18 tea infusions, and higher than $1.0 \mathrm{mg} / \mathrm{L}$ in 5 out of 18 tea infusions.

3.1. Comparison with Previous New Zealand Studies. The only other study to publish F levels in BT in NZ dates to 1949 [68]. In this study, the author reported that almost all teas imported to NZ at this time were from either Ceylon (Sri Lanka) or India. Samples of both types of orthodox loose tea (4 in total) were obtained and the F content was measured in infusions. The weights of tea per infusion were selected to cover the range for most tea tastes and varieties. The weights of tea to water were $6.75 \mathrm{~g} / \mathrm{L}, 10 \mathrm{~g} / \mathrm{L}$, and $15.0 \mathrm{~g} / \mathrm{L}$ to represent light, medium, and strong tea. Samples were infused for 3 and 10 minutes with tap water with a F content of $0.05 \mathrm{mg} / \mathrm{L}$. At 3 minutes' infusion time, the $\mathrm{F}$ content was reported to range from 0.46 to $1.26 \mathrm{mg} / \mathrm{L}$ increasing with strength of brew. At 10 minutes, the $\mathrm{F}$ content was reported to range from 0.48 to $1.69 \mathrm{mg} / \mathrm{L}$. The lowest F levels were found in North Indian teas and the highest in Ceylon teas. The author reported that, based on the daily ration of $8.1 \mathrm{~g}$ of tea per day, $\mathrm{F}$ intake from tea would range from 0.5 to $1.0 \mathrm{mg} /$ day [68].

3.2. Exposure Assessment. As we previously reported [10], there is some controversy regarding recommendations on Adequate Intake (AI) for $\mathrm{F}$ since there are no signs of $\mathrm{F}$ deficiency which have been identified in humans, and F has no known essential function in human growth and development [115]. Evidence over the last 20 years has demonstrated that the cariostatic effect of $\mathrm{F}$ is topical on the tooth surface and ingestion is not required [116-118]. In 2011, the EFSA commissioned the University of East Anglia to examine the scientific data from which dietary reference values (DRVs) for $\mathrm{F}$ may be derived. The comprehensive review found that there were relatively few studies of good quality regarding $\mathrm{F}$ intake, accumulation, and/or health endpoints. The review concluded that there was a lack of high quality evidence upon which DRVs may potentially be based for F [119]. Notwithstanding this, the EFSA have recommended that the AI for a healthy adult woman is $2.9 \mathrm{mg} /$ day and $3.4 \mathrm{mg}$ per day for a healthy adult male [120]. In the USA, the Institute of Medicine has recommended that the $\mathrm{AI}$ is $3.0 \mathrm{mg}$ and $4.0 \mathrm{mg}$ 
TABLE 2: Summary of fluoride intake per cup for 18 black teabag commodities.

\begin{tabular}{|c|c|c|c|c|c|c|c|}
\hline \multirow[t]{2}{*}{ Cups per day } & \multirow[t]{2}{*}{$\begin{array}{l}\text { Volume } \\
\text { (mls/day) }\end{array}$} & \multicolumn{2}{|c|}{$\begin{array}{c}\text { Tea infusions made with } \\
\text { nonfluoridated water } \\
(0.00 \mathrm{mg} / \mathrm{L}) \\
\text { Total F intake }\end{array}$} & \multicolumn{2}{|c|}{$\begin{array}{l}\text { Tea infusions made with } \\
\text { fluoridated water } \\
(0.70 \mathrm{mg} / \mathrm{L}) \\
\text { Total F intake }\end{array}$} & \multicolumn{2}{|c|}{$\begin{array}{c}\text { Tea infusions made } \\
\text { with fluoridated water } \\
(1.0 \mathrm{mg} / \mathrm{L}) \\
\text { Total F intake }\end{array}$} \\
\hline & & $\begin{array}{c}\text { Max } \\
\text { mg/day }\end{array}$ & $\begin{array}{c}\text { Min } \\
\text { mg/day }\end{array}$ & $\begin{array}{c}\text { Max } \\
\text { mg/day }\end{array}$ & $\begin{array}{c}\text { Min } \\
\text { mg/day }\end{array}$ & $\begin{array}{c}\text { Max } \\
\text { mg/day }\end{array}$ & $\begin{array}{c}\text { Min } \\
\text { mg/day }\end{array}$ \\
\hline 1 & 250 & 0.8 & 0.1 & 1.0 & 0.2 & 1.1 & 0.3 \\
\hline 2 & 500 & 1.6 & 0.2 & 2.0 & 0.5 & 2.3 & 0.8 \\
\hline 3 & 750 & 2.4 & 0.3 & 2.9 & 0.7 & 3.2 & 0.9 \\
\hline 4 & 1000 & 3.2 & 0.4 & 3.9 & 0.9 & 4.2 & 1.2 \\
\hline 6 & 1500 & 4.8 & 0.6 & 5.9 & 1.4 & 6.3 & 1.8 \\
\hline 8 & 2000 & 6.4 & 0.8 & 7.8 & 1.8 & 8.4 & 2.4 \\
\hline 10 & 2500 & 8.0 & 1.0 & 9.8 & 2.3 & 10.5 & 3.0 \\
\hline 12 & 3000 & 9.6 & 1.2 & 11.7 & 2.7 & 12.6 & 3.6 \\
\hline 14 & 3500 & 11.2 & 1.4 & 13.7 & 3.2 & 14.7 & 4.2 \\
\hline
\end{tabular}

In the 28 member countries of the EU, the AI for a healthy adult female is $2.9 \mathrm{mg} /$ day and $3.4 \mathrm{mg}$ per day for a healthy adult male [121]. In the USA, the AI is $3.0 \mathrm{mg}$ and $4.0 \mathrm{mg}$ per day, respectively [122].

per day, respectively [121]. In the EU, the Tolerable Upper Intake Level (UL) for $\mathrm{F}$ has been established at $7 \mathrm{mg} /$ day for adults [122].

According to the EFSA (2010), an AI is the average observed daily level of intake by a population group (or groups) of apparently healthy people that is assumed to be adequate, while chronic intakes above the UL may be associated with an increased risk of adverse effects [123]. In general, the AI for $\mathrm{F}$ are based on estimated intakes that have been shown to reduce the occurrence of dental caries maximally in a population without causing unwanted side effects including moderate dental fluorosis [122]. The AI and UL apply to intake from all sources including water, beverages, foodstuffs, dental health products, and drugs. The Scientific Committee on Health and Environmental Risks (SCHER) reported that the emerging picture from all risk assessments conducted on $\mathrm{F}$ is that there exists a narrow margin between the recommended intakes for the prevention of dental caries and the upper limits of exposure [124]. In view of the different health, nutritional status and habits of individuals in addition to the differing consumption of drinking water and the uncontrolled intake of $\mathrm{F}$ from other sources, such as tea, medications, or occupational exposures, it is difficult to accurately define an AI or UL for a population without excluding sensitive subgroups of the population. To illustrate this dilemma, the intake of $\mathrm{F}$ for individuals with low iodine status or poor renal function poses significantly higher risk of negative outcomes than for healthy individuals [2].

While this study is the first to measure F concentration in a wide range of commercial BT products available in $\mathrm{NZ}$, it is important to note that the exposure assessment presented here is specific to adult consumption of tea in NZ and excludes all other sources of dietary F intake. Clearly, any estimation of $\mathrm{F}$ intake from tea is dependent on total volume consumed. Recent consumer surveys in both Australia and NZ have found that the clear majority of tea drinkers prefer to drink tea in a mug rather than a cup $[125,126]$. A standard cup size in Australia is the same as the USA ( $250 \mathrm{ml})$; however, the market trend in the past two decades is for larger mug sizes ranging from 350 to $600 \mathrm{ml}$.

In this study, we have selected $350 \mathrm{ml}$ to be representative of mug volumes. The variation in cup sizes is important in characterizing risk. For example, the standard tea cup size in Turkey is just $75 \mathrm{ml}$ [127], which is significantly less than that for Western countries. Notably, per capita consumption of black tea in Turkey is reported to be approximately twice that of NZ and three times that of Australia [1]. However, black tea intake, in terms of daily volume of tea infusion consumed, is significantly higher in Australia [33] than Turkey [127]. This reflects the differences in cup sizes as well as the differences in tea products used to prepare tea infusions. For example, in Turkey, orthodox loose tea remains the tea product of choice [127].

In this current study, the dose of $\mathrm{F}$ in tea infusions for each brand of tea was calculated for a range of consumption scenarios ranging from 1 cup to 14 cups per day based on data on tea consumption among pregnant women in NZ reported by Ford et al. (1998) [128].

The results are provided in Table 2. It is notable that, depending on cup size, the consumption of 14 cups of tea per day would equate to 2.8 to $3.5 \mathrm{~L}$ of tea per day. Based on this NZ data, we have assumed that $3.5 \mathrm{~L}$ per day is the reasonable maximum exposure (RME) in our study for tea consumption in NZ. The RME is considered conservative as several studies in the United States have reported individuals consuming 3.5-7.5 L of BT per day [129-131].

In Table 3, the estimated $\mathrm{F}$ intake per mug of tea consumed is presented. The F levels reported represent the measured $\mathrm{F}$ concentrations in tea infusion prepared with drinking water containing $0.7 \mathrm{mg} / \mathrm{L}$ F.

Considering that the upper level of $\mathrm{F}$ in drinking water permitted in $\mathrm{NZ}$ is $1.0 \mathrm{mg} / \mathrm{L}$, an approximate estimate of $\mathrm{F}$ intake has also been provided to allow for the differences in $\mathrm{F}$ 
TABLE 3: Summary of fluoride intake per mug for 18 black tea bag commodities.

\begin{tabular}{|c|c|c|c|c|c|c|c|}
\hline \multirow[t]{2}{*}{ Mugs per day } & \multirow[t]{2}{*}{$\begin{array}{l}\text { Volume } \\
\text { (mls/day) }\end{array}$} & \multicolumn{2}{|c|}{$\begin{array}{c}\text { Tea infusions made with } \\
\text { nonfluoridated water } \\
(0.00 \mathrm{mg} / \mathrm{L}) \\
\text { Total F intake }\end{array}$} & \multicolumn{2}{|c|}{$\begin{array}{c}\text { Tea infusions made with } \\
\text { fluoridated water } \\
(0.70 \mathrm{mg} / \mathrm{L}) \\
\text { Total F intake }\end{array}$} & \multicolumn{2}{|c|}{$\begin{array}{c}\text { Tea infusions made with } \\
\text { fluoridated water } \\
(1.0 \mathrm{mg} / \mathrm{L}) \\
\text { Total F intake }\end{array}$} \\
\hline & & $\begin{array}{c}\text { Max } \\
\text { mg/day }\end{array}$ & $\begin{array}{c}\text { Min } \\
\text { mg/day }\end{array}$ & $\begin{array}{c}\text { Max } \\
\text { mg/day }\end{array}$ & $\begin{array}{c}\text { Min } \\
\text { mg/day }\end{array}$ & $\begin{array}{c}\text { Max } \\
\text { mg/day }\end{array}$ & $\begin{array}{c}\text { Min } \\
\text { mg/day }\end{array}$ \\
\hline 1 & 350 & 1.1 & 0.1 & 1.4 & 0.3 & 1.5 & 0.4 \\
\hline 2 & 700 & 2.2 & 0.3 & 2.7 & 0.6 & 2.9 & 0.8 \\
\hline 3 & 1050 & 3.0 & 0.4 & 4.1 & 0.9 & 4.4 & 1.3 \\
\hline 4 & 1400 & 4.5 & 0.6 & 5.5 & 1.3 & 5.9 & 1.7 \\
\hline 6 & 2100 & 6.7 & 0.8 & 8.2 & 1.9 & 8.8 & 2.5 \\
\hline 8 & 2800 & 9.0 & 1.1 & 10.9 & 2.5 & 11.8 & 3.4 \\
\hline 10 & 3500 & 11.2 & 1.4 & 13.7 & 3.2 & 14.7 & 4.2 \\
\hline
\end{tabular}

In the 28 member countries of the EU, the UL for a healthy adult male or female is $7.0 \mathrm{mg} / \mathrm{day}$ [123]. In the USA, the UL is $10.0 \mathrm{mg}$ per day [122].

levels. Thus, the reported levels represent the lower and upper range for the 18 products tested.

Based on our results, assuming the consumption of one normal mug of tea liquor/infusion per day, we estimate that the daily $F$ intake will range from 0.1 to $1.1 \mathrm{mg} /$ day for nonfluoridated communities and 0.3 to $1.5 \mathrm{mg} /$ day for fluoridated communities. Assuming that the consumption is of 2-4 mugs, we calculate the daily intake from tea to be in the range from 0.3 to $4.5 \mathrm{mg} /$ day in nonfluoridated communities and $0.6-5.9 \mathrm{mg} /$ day in fluoridated communities. For high tea drinkers consuming of 6-10 mugs per day, the F intake would range from 0.8 to $11.2 \mathrm{mg}$ per day for nonfluoridated communities and 1.9 to $14.7 \mathrm{mg} /$ day for fluoridated communities.

Taking the highest tea intake reported by Ford et al. (1998) among NZ pregnant women (14 cups per day) [128], $\mathrm{F}$ intake from tea would range from 1.4 to $11.2 \mathrm{mg} /$ day in nonfluoridated communities and from 3.2 to $14.7 \mathrm{mg} /$ day in fluoridated communities.

However, exposure assessment should be representative of actual consumer preference. As Bell tea has the largest market share in NZ [111], representing the main brand of choice among consumers [54], the intakes associated with the two Bell tea products more accurately reflect consumer preference and exposure. Taking this into consideration, we have evaluated the contribution of the two Bell tea products to AI and UL intake reference values. The percentage contribution of each brand to AI and UL was calculated using Microsoft Excel. The values reported reflect the $\mathrm{F}$ content of drinking water $(0.7-1.0 \mathrm{mg} / \mathrm{L})$ as recommended by the NZ Ministry of Health.

A summary of exposure and risk estimates for $\mathrm{F}$ intake is presented in Table 4 . The values do not include additional dietary exposure from other beverages, food, toothpaste or dental products, medications, or occupational exposures. The results reported in this study demonstrate that a single mug of Bell Kenyan tea when prepared with fluoridated tap water can provide half the daily AI for a healthy female, excluding all other sources of F intake. Two mugs of Bell Kenyan tea can provide the full AI. The consumption of 10 mugs or 14 cups of Bell Kenyan tea can exceed the AI 5-fold and the UL 2-fold for a healthy adult female.
For Bell original black tea, the results are similar though marginally lower. For an adult male, one mug of Bell Kenyan tea per day can provide up to $44 \%$ of the recommended AI with Bell Original Tea providing up to $38 \%$ of the AI. Two mugs per day would provide between 79 and $85 \%$ of the AI and up to $37 \%$ of the UL for a healthy adult male. Notably, for the two major supermarket own brand BT bags, the results would be similar, though marginally lower.

\section{Discussion}

4.1. Factors That Influence the Fluoride Content in Manufactured Tea and Tea Infusions. Many factors influence the concentration of elements including $\mathrm{F}$ in tea plants and its product including cultivar type and growth conditions (soil pH; the $\mathrm{F}$ and aluminium contents and their forms in soils; rainfall, altitude, air, and soil pollution from industrial sources and urban activities), horticultural practices (the application of chemical and organic fertilizers, use of pesticides and soil conditioners, the F content of water used for irrigation, mechanical or hand plucking, and age of leaves), the period of withering, and the mechanical processes used in the treatment and packaging of tea [36, 132-150].

The primary factors affecting the amount of total watersoluble $\mathrm{F}$ in tea infusions are the temperature of water used for brewing, particle size, brewing time, water hardness, and background levels of F in drinking water [138, 143, 151-156].

Typically, the higher the temperature of water, the higher the diffusion of $\mathrm{F}$; the smaller the particle size the greater the rates of diffusion. In this context, it is worth noting that one of the most widely reported incidences of chronic tea ingestion and skeletal fluorosis from tea involves that of an American woman as reported by Kakumanu and Rao (2013). In this case study, it was reported that the patient used 100 to 150 teabags daily to prepare a tea infusion for consumption [157]. However, the authors did not clarify how the tea was brewed and no measurement was made of the $\mathrm{F}$ content in the tea infusion. It was subsequently indicated (D. S. Rao, personal communication, December 23, 2014) that the patient made iced tea by steeping the teabags in cold water at room temperature. 
TABLE 4: Summary of fluoride intake from Bell tea products for NZ adults as a percentage of AI and UL based on EU dietary reference.

\begin{tabular}{|c|c|c|c|c|c|c|c|}
\hline & $\begin{array}{l}350 \mathrm{ml} \\
1 \mathrm{mug}\end{array}$ & $\begin{array}{l}700 \mathrm{ml} \\
2 \mathrm{mugs}\end{array}$ & $\begin{array}{l}1050 \mathrm{ml} \\
3 \mathrm{mugs}\end{array}$ & $\begin{array}{l}1400 \mathrm{ml} \\
4 \mathrm{mugs}\end{array}$ & $\begin{array}{l}2100 \mathrm{ml} \\
6 \mathrm{mugs}\end{array}$ & $\begin{array}{l}2800 \mathrm{ml} \\
8 \mathrm{mugs}\end{array}$ & $\begin{array}{l}3500 \mathrm{ml} \\
10 \mathrm{mugs}\end{array}$ \\
\hline \multicolumn{8}{|l|}{ Bell Kenya Bold } \\
\hline F intake (mg/day) & $1.4-1.5$ & $2.7-2.9$ & $4.1-4.4$ & $5.5-5.9$ & $8.2-8.8$ & $10.9-11.8$ & $13.7-14.7$ \\
\hline \multicolumn{8}{|l|}{$\%$ of $A I$} \\
\hline Adult female & $47-51 \%$ & $94-100 \%$ & $141-152 \%^{\ddagger}$ & $188-203 \%$ & $282-303 \%$ & $377-406$ & $471-506 \%$ \\
\hline Adult male & $40-44 \%$ & $79-85 \%$ & $120-130 \%^{\ddagger}$ & $161-173 \%$ & $241-259 \%$ & $321-345 \%$ & $401-432 \%$ \\
\hline \multicolumn{8}{|l|}{$\%$ of $U L$} \\
\hline Adult both sexes & $20-21 \%$ & $39-42 \%$ & $59-63 \%$ & $78-84 \%$ & $117-126 \%^{\dagger}$ & $156-168 \%$ & $195-210 \%$ \\
\hline \multicolumn{8}{|l|}{ Bell Original Tea } \\
\hline F intake (mg/day) & $1.2-1.3$ & $2.4-2.6$ & $3.6-3.9$ & $4.8-5.2$ & $7.1-7.8$ & $9.5-10.4$ & $11.9-13.0$ \\
\hline \multicolumn{8}{|l|}{$\%$ of $A I$} \\
\hline Adult female & $41-45 \%$ & $82-89 \%$ & $123-134 \%^{\ddagger}$ & $164-179 \%$ & $246-268 \%$ & $328-357 \%$ & $410-447 \%$ \\
\hline Adult male & $35-38 \%$ & $70-76 \%$ & $105-114 \%^{\ddagger}$ & $140-152 \%$ & $210-229 \%$ & $280-305 \%$ & $350-381 \%$ \\
\hline \multicolumn{8}{|l|}{$\%$ of $U L$} \\
\hline Adult both sexes & $17-19 \%$ & $34-37 \%$ & $51-56 \%$ & $68-74 \%$ & $102-111 \%^{\dagger}$ & $136-148 \%$ & $170-185 \%$ \\
\hline
\end{tabular}

${ }^{\ddagger}$ Excluding all other sources of dietary F intake, the consumption of more than 2 mugs of Bell tea products will exceed the AI for healthy adult males and females. ${ }^{\dagger}$ Consumption of 6 mugs will exceed the UL.

To better understand how water temperature affects the diffusion of $\mathrm{F}$ from teabags, we compared the $\mathrm{F}$ levels in different BT infusions from commercial teas with hot (boiling water for 5 minutes) or cold (room temperature for 20 minutes) water. The infusible $\mathrm{F}$ level in the cold brew using 50 teabags (each teabag containing $3.5 \mathrm{~g}$ of tea) in $3 \mathrm{~L}$ of tap water after 20 minutes was $3.2 \mathrm{mg} / \mathrm{L}$, compared to $5.6 \mathrm{mg} / \mathrm{L}$ for a single teabag of the same brand left to brew in boiling water for 5 minutes (data not provided). The standard weight of a teabag in the USA is $2 \mathrm{~g}$; thus, the 50 teabags used in this experiment would be equal in weight to 75 teabags in the USA. What this demonstrates is that it is not the quantity of teabags that is relevant but the $\mathrm{F}$ content in the tea infusions, which is primarily influenced by the temperature of brewing.

It is also important to be aware that, in the Far East (particularly China and Japan), the brewing temperature of green tea is typically $70 \sim 80^{\circ} \mathrm{C}$. In contrast, black tea is brewed using boiling water. In addition, the Chinese believe that the second infusion tastes better than the first. This has led some green tea manufacturers to recommend that the first infusion be discarded and the second infusion consumed [140]. According to infusion experiments, the F content in the second infusion is approximately $20 \%$ of that present in the original infusion [153]. Hence, the F content in the original tea leaf or original infusion may not be representative of actual $\mathrm{F}$ intake. Clearly cultural influences in Asia in how tea is prepared and consumed vary significantly from Western countries, and the culture of preparing tea by continuous or repeated infusions prior to consumption can greatly influence F exposure.

Regarding Western practices of preparing tea in a pot or mug significant differences may occur depending on individual consumer habits and tastes. In experimental settings, the majority of studies use a steep time of 5 minutes to represent the realistic maximum time used by consumers and recommendations by tea brands. However, in a real-life scenario, a general consumer is unlikely to monitor the exact amount of time that their tea is steeping. Steep times will likely increase when preparing a pot of tea, compared to use of instant teabags in a mug, and use of more than one teabag is a widespread practice when preparing a pot of tea. Individual variations in tea making in Western countries among teabag users can also differ significantly. Some add boiling water and just leave the teabag(s) to float for a given time. Others move the teabag up and down (dunking) or agitate the teabag with a spoon. Ducking or agitating the teabag will increase the diffusion rate. Hence, higher $\mathrm{F}$ levels in infusions are expected when preparing tea in this manner. Past studies have shown that most $\mathrm{F}$ is rapidly extracted from teabags in the first minute and slowly increases with time. The concentration of total $\mathrm{F}$ extracted at 5 minutes is comparable to that at 10 minutes and 15 minutes $[151,152]$.

Previous studies have shown that the addition of milk to tea (English style tea) has no effect on the leachability of F from tea [158-161]. Clearly, as identified in our study, the use of fluoridated tap water to make tea infusions contributes significantly to the total F content in tea beverages. Another factor that influences $\mathrm{F}$ content in infusion is cup size. The larger the cup size, the greater the volume of beverage consumed and the greater the potential $\mathrm{F}$ intake. A cup of tea could be $30 \mathrm{ml}$ as in Senegal [162] and China [163]; $80 \mathrm{ml}$ as in Saudi Arabia [164]; $80-100 \mathrm{ml}$ as in India [165]; $100 \mathrm{ml}$ as in Japan [166], Turkey [167], and Iran [168]; $135 \mathrm{ml}$ as in Italy [169]; $240 \mathrm{ml}$ ( $8 \mathrm{oz}$ mug) as in the USA or in the case of iced tea the amount is larger $(360 \mathrm{ml})$ [170]. In the RoI, UK, Australia, and NZ, tea is mainly consumed in mugs. There are no standardized mug sizes; however, they generally range from 250 to $400 \mathrm{ml}$. It is noteworthy that studies on the extraction efficiencies of caffeine from brewed teas found that when BT or GT teabags were brewed in a larger serving size, the extraction efficiencies increase [171]. 
4.2. Temporal Changes in Exposure to Fluoride in Tea Beverages. In exposure science, one must consider temporal changes. In recent decades, there have been major changes in production practices in tea cultivation and harvesting that contribute to higher $\mathrm{F}$ levels in tea products. The use of agrichemicals and mechanization of harvesting has increased dramatically in recent decades and more recently climate change has also influenced tea production and quality. However, in considering temporal changes, one must also examine if the sources of tea have changed in recent decades. In this context, it is important to note that, since the 1960s, the source of BT marketed and consumed internationally has dramatically changed. Prior to the 1960s, the most BT available in Western countries originated in India and Sri Lanka. To meet demand for cheaper quality tea and increased production, tea cultivation increased dramatically in East Africa (principally Kenya) from the 1960s and international tea companies increasingly relied on Kenya to source BT products. Tea production has also increased significantly in Argentina to meet the demands of USA market [172]. Several studies have found a clear distinction in the heavy metal characteristics of teas produced in African (Kenyan) tea compared to Asian teas (China, Japan, Sri Lanka, and India) $[137,139,173]$. This could also have implications for residue levels of $\mathrm{F}$ in tea.

It is noteworthy that food safety authorities in China recently imposed restrictions on most of Kenya's tea products due to potentially hazardous concentrations of $\mathrm{F}$ found in some of their tea products [174]; however, to our knowledge, no restrictions have been implemented by any other country. In our previous study, we also reported that the highest concentrations of F in BT products available in Ireland were found in Kenyan teas, which represent the most blended BT products in Ireland and the UK and the lowest in teas from Sri Lanka [10]. In this study, we also found that NZ teas originating from Kenya had the highest $\mathrm{F}$ level and teas originating from Sri Lanka had the lowest F content. While tea from Kenya has been the major source of tea in Ireland since the 1970s, it has not been reported in literature when tea sourced from Kenya was first introduced to the NZ tea market.

A second factor that has increased consumer exposure to $\mathrm{F}$ from $\mathrm{BT}$ was been the rapid rise in popularity of teabags, from the 1970 onwards. The CTC process has become especially popular as the teabag market developed [175]. Prior to 1970, orthodox leaf tea was the dominant form in which tea was consumed. Today, consumption in industrial countries is now predominantly in teabag form. For example, in the Republic of Ireland, 95\% of the tea is sold in teabags (CTC black tea) with the orthodox loose tea leaf market representing just 3 to $4 \%$ [176]. NZ is similar to the UK and Ireland, with $94 \%$ of consumers purchasing black teabags [54]. In contrast, orthodox loose tea is still the predominant type of tea consumed in many Asian and Middle Eastern countries. For example, in Turkey, teabags constitute just $5-10 \%$ of the tea market [177].

Considering that higher $\mathrm{F}$ content has been found in BT infused in teabags than loose orthodox BT $[6,134,150]$, it would appear that the introduction of the black CTC teabags to international tea markets post-1970 and the change in origin of imported tea significantly altered population exposure to $\mathrm{F}$. This is evident in the differences in $\mathrm{F}$ levels reported in our study with those reported for BT products in NZ during the 1940s [68]. In NZ, population exposure was further exacerbated by the rapid expansion of water fluoridation in the 1960s.

4.3. Bioavailability of Fluoride from Tea. The first study to accurately quantify bioavailability of $\mathrm{F}$ by tea was by Toyota (1979) [178]. In this study, the authors demonstrated among subjects aged 15 to 59 years of age that the consumption of $300 \mathrm{ml}$ of orthodox BT infusion containing $1.40 \mathrm{mg}$ of F was found to increase background serum F levels 5-fold ( 0.526 to $2.78 \mu \mathrm{mol} / \mathrm{L}$ ) within $1 \mathrm{hr}$. Within $3 \mathrm{hrs}$, urinary F concentrations increased 7-fold from $0.5 \mathrm{mg} / \mathrm{L}$ to $3.5 \mathrm{mg} / \mathrm{L}$ and declined to $1.5 \mathrm{mg} / \mathrm{L}$ six hours after consumption [178]. More recently, Chan (2014) undertook a bioavailability assessment of $F$ in three UK black tea infusions prepared from two different brands of teabags and one brand of loose leaf tea. The order of percentage $\mathrm{F}$ bioaccessibility in the tea products and infusions was economy BT bags > BT bags > pure orthodox BT leaf tea. For the economy BT bag products, up to $103.8 \%$ of the $\mathrm{F}$ appeared to be available for absorption in the gastric fraction and $109.4 \%$ in the gastrointestinal fraction. In the leaf tea products, the results were $83.2 \%$ and $97.5 \%$, respectively [179]. These findings somewhat confirm previous results from animal studies which demonstrated that $F$ uptake in bone was significantly higher from tea infusions prepared from teabags with a $\mathrm{F}$ content of $2.6 \mathrm{mg} / \mathrm{L}$ than from fluoridated tap water containing the same F content after a period of just 30 days [180]. Another factor that contributes to F bioavailability is caffeine. Chan et al. (1988) found that coexposure to caffeine and $\mathrm{F}$ resulted in significantly increased bioavailability of $\mathrm{F}$ in humans, as measured by plasma F levels, compared to subjects exposed to $\mathrm{F}$ alone [181]. It is important to note that tea is also a rich source of caffeine [182].

Based on this evidence and that previously discussed we hypothesise that the bioavailability of F from BT manufactured by CTC is higher than orthodox tea. We further suggest that this enhanced bioavailability may also be associated with the minute tea leaf particle size in CTC tea which can be released from the teabag as dust into the tea infusion and ingested, thereby contributing to the overall exposure of a consumer.

4.4. The Association between Fluoride Intake, Tea, and Skeletal Fluorosis. Once F is absorbed by ingestion, it passes into the blood for distribution throughout the body and for partial excretion [183]. However, inorganic $\mathrm{F}$ is a persistent bioaccumulator, and the ever-increasing use (and release) of $\mathrm{F}$ compounds in the environment should be of long-term concern in population subgroups who are most susceptible and, therefore, most "at risk" [184]. The WHO (2000) reported that skeletal fluorosis is associated with a systemic uptake exceeding $5 \mathrm{mg} /$ day in a relatively sensitive section of the general population [185]. Thus, the question of the bioavailability and additive toxicity of $\mathrm{F}$ from tea is important particularly in countries with water fluoridation. 
The USA NRC (2006) reported that, in the absence of other sources of $\mathrm{F}$ (i.e., tea or toothpaste), the consumption of drinking water with a $\mathrm{F}$ level of $1 \mathrm{ppm}$, bone $\mathrm{F}$ levels can reach $2,500 \mathrm{mg} / \mathrm{kg}$ in twelve years and to 3,000 to $4,000 \mathrm{mg} / \mathrm{kg}$ over longer periods [2]. Moreover, the committee observed that evidence suggests that preclinical bone changes and symptoms of clinical stages I and II skeletal fluorosis may occur with bone concentrations above $3,500 \mathrm{mg} / \mathrm{kg}$ [2]. Stage II skeletal fluorosis is associated with chronic joint pain, arthritic symptoms, slight calcification of ligaments, and osteosclerosis of cancellous bones [2]. In studies, which have measured bone $\mathrm{F}$ levels in nonfluoridated and fluoridated communities in the USA, UK, Canada, and Finland, significant variations were observed. For example, Weatherell (1966) measured the F levels in femoral compacta from humans of different ages who lived in communities supplied with drinking water containing $<0.5 \mathrm{ppm} \mathrm{F}$ in various locations in England and Rochester, New York. Significant differences were found between the two populations, with F accumulating to 4,000 ppm among the English subjects compared to less than 1,000 ppm among residents in Rochester [186]. Since drinking water in both communities was nonfluoridated $(<0.5 \mathrm{ppm})$, the fourfold difference in bone F levels reported clearly reflects the higher consumption of tea in England compared to the US [1]. As noted previously, Jackson and Weidman (1958) observed that tea drinking in the UK was a significant factor in bone $\mathrm{F}$ levels regardless of drinking water F levels [30].

A study performed in Finland in 1985 found that bone F concentrations were typically 3 -fold higher in adult subjects (mean age $60 \mathrm{yrs}$ ) who had resided in a fluoridated community for 20 years compared with subjects from nonfluoridated areas [187]. In men, the highest concentration was $2750 \mathrm{ppm}$. In women, the highest concentration of $\mathrm{F}$ in bone was found in a subject with impaired renal function (3890 ppm) [187]. However, it is important to note that tea consumption is uncommon in Finland and the subjects had not ingested fluoridated water throughout their lifetime. Moreover, the study would not have included exposure from fluoridated toothpaste, which only became widely available from the 1980s onwards. Mostafaei et al. (2015) found that the rate of increase in bone fluorine content per year was 3-fold higher for tea drinkers in Canada compared to nontea drinkers [188]. However, it should also be noted that per capita consumption of black tea in NZ is twofold higher than Canada and fourfold higher than Finland [1].

In Switzerland, Boillat et al. (1980) in a study examining occupation exposures to $\mathrm{F}$ found that as bone $\mathrm{F}$ levels increased, the frequency of joint pain and stiffness increased [189]. This joint pain resulted in disability in some cases. Radiological findings of a higher frequency of ossification of the attachment of ligament, tendon, and muscle to bone were observed in exposed workers compared to workers of similar age and physical activities but without significant occupational exposure to $\mathrm{F}$ [189]. The anatomical regions with the highest prevalence of this condition were the heel, hips, spine, forearm, knee, and hand. Up to $100 \%$ of the $\mathrm{F}$ exposed workers had evidence of skeletal ossification. In this study, the mean age of workers was 61 years and the mean bone $\mathrm{F}$ content in the $\mathrm{F}$ exposed workers was 5,617 ppm $(\mathrm{SD}=2,143 \mathrm{ppm})$ [189]. Wang et al. (1994) reported similar radiological findings in 127 patients from mainland China (mean age 43 years) with clinically proven skeletal fluorosis [190].

In a study conducted in Inner Mongolia, Li et al. (2009) reported that when drinking water $\mathrm{F}$ levels were $0.70 \mathrm{mg} / \mathrm{L}$ and the mean F content of tea was $1.81 \mathrm{mg} / \mathrm{L}, 31 \%$ of habitual tea drinkers were found to have skeletal fluorosis [191]. Cao et al. (1996) reported that the consumption of tea infusions with a $\mathrm{F}$ concentration of $2.59 \mathrm{mg} / \mathrm{L}$ led to an epidemic of fluorosis among Tibetans [192]. The F level in drinking water was $0.11 \mathrm{mg} / \mathrm{L}$ and tea consumption was found to contribute $>90 \%$ of the daily dietary intake of F. Among the 685 adult subjects examined, $31.5 \%$ showed signs of skeletal fluorosis. Of these, $8.1 \%$ were classified as Grade I, 22.5\% as Grade II, and $0.9 \%$ as Grade III. Frequency of manifested symptoms included $39.2 \%$ with joint pain; $26.1 \%$ with lumbago; $16.9 \%$ with numbness in the extremities; $4.1 \%$ with tetany; and $3.8 \%$ with hand and foot rigidity [192]. Wang et al. (1994) found that symptoms most prevalent among adult subjects with skeletal fluorosis were lower back pain, followed by leg pain, joint dysfunction, arm pain, hand tingling, and neck pain [190]. In a study conducted in Thailand, Namkaew and Wiwatanadate (2012) found a significant association between daily $\mathrm{F}$ intake and lower back pain and suggested that this could be deemed as the early stage of mild skeletal fluorosis caused by joint or bone degeneration [193].

In the UK, where tea drinking is common, excessive $\mathrm{F}$ intake from BT consumption has been found to be associated with chronic arthritis [194]. The author concluded that some cases of pain diagnosed as rheumatism or arthritis may be due to subclinical fluorosis which is not radiologically demonstrable [194]. Similarly, Carnow and Conibear (1981) reported that clinical musculoskeletal effects could occur before skeletal fluorosis becomes apparent radiographically [195]. Consistent with the UK study, numerous other researchers have also found an association between $\mathrm{F}$ intake and osteoarthritis [193, 196-203]. Most notably, Ge et al. (2006) in a large-scale study from China found that the rate of osteoarthritis was significantly increased at water $\mathrm{F}$ levels of just $1.7 \mathrm{mg} / \mathrm{L}$ [196], a concentration within the range of $\mathrm{F}$ measurement reported in this study for tea beverages in NZ.

In the USA, researchers in a recent large-scale study of 76,000 US women with ages ranging from 50 to 79 found that women who drink greater than 4 cups of black tea per day have a $78 \%$ greater chance of developing rheumatoid arthritis compared to those women who never drink tea. They also reported that women who consume any amount of black tea, even small quantities, per day, have a $40 \%$ risk of developing RA [204]. A previous USA study involving predominantly white women aged 55-69 years found that drinking 1-3 cups of tea per day increased the risk of RA, while consuming more than 3 cups per day reduced the risk. The category of tea, however, was not identified [205].

In Sweden, Tettamanti et al. (2011) found an association between tea but not coffee consumption and bladder pain syndrome in women [206]. Unlike smoking, this association was not found to be confounded by genetic factors. Moreover, 
in Turkey, Seferoglu et al. (2012) found that consumption of more than 4 cups of tea was risk factor for chronification of migraine [207]. Based on Turkish consumption, this would equate to approximately $400 \mathrm{ml}$ of tea [167], which is less than the average intake of BT in NZ.

In addition to bone $\mathrm{F}$ levels, blood $\mathrm{F}$ levels have been widely used a biomarker of $\mathrm{F}$ exposure and indicator of skeletal fluorosis. Xiang et al. (2005) demonstrated that longterm exposure to $\mathrm{F}$ resulting in fasting serum $\mathrm{F}$ concentrations ranging from 2.5 to $8.0 \mu \mathrm{mol} / \mathrm{L}$ can result in chronic $\mathrm{F}$ intoxication and stage I and stage II skeletal fluorosis [208]. Several international studies have confirmed this association. In a study conducted in Turkey, Savas et al. (2001) found that the mean serum $\mathrm{F}$ levels in 56 patients with endemic fluorosis were $5.27 \mu \mathrm{mol} / \mathrm{L}$ with knee joint being the most commonly diagnosed abnormality, followed by lower back pain and hip, feet, shoulder, and neck pain [203]. In India, Susheela and Bhatnagar (2002) in a hospital based study diagnosed symptoms of skeletal and nonskeletal fluorosis in patients aged 8 to 60 years of age with serum $F$ levels ranging from 2.1 to $5.0 \mu \mathrm{mol} / \mathrm{L}$ [209]. Symptoms included pain and rigidity in the joints, nonulcer dyspepsia, and gastrointestinal complaints such as nausea, vomiting, pain in the stomach, bloated feeling/gas formation in the stomach, constipation followed by diarrhoea, polyuria and polydipsia, and muscle weakness and fatigue. In another study conducted in India, Harinarayan et al. (2006) documented fluorotoxic metabolic bone disease (FMBD) in 8 patients aged 12 to 58 years with serum $\mathrm{F}$ levels ranging from 1.05 to $4.7 \mu \mathrm{mol} / \mathrm{L}$ [210]. Notably, the authors found that FMBD was associated with severe osteomalacia due to mineralization defects predominantly caused by nephrogenic hypocalcemia and hypophosphatemic defects due to renal tubular damage caused by $\mathrm{F}$ [210].

In the USA, Whyte et al. (2008) reported a case study of an American woman who developed skeletal fluorosis from excessive tea consumption. Her fasting serum F level was $6.3 \mu \mathrm{mol} / \mathrm{L}$ before the patient stopped drinking instant tea [130]. Four months after discontinuing tea consumption her fasting serum $F$ levels reduced to $<1 \mu \mathrm{mol} / \mathrm{L}$ and the patient's pains resolved over several years after she stopped drinking instant tea [130]. Hallanger Johnson et al. (2007) presented case studies of four American women (50 to 67 years of age) who developed F-related bone disease and associated chronic pain from excessive tea consumption [129]. Among the four patients, serum $F$ levels were found to range from 10.2 to $19.0 \mu \mathrm{mol} / \mathrm{L}$. In all cases reduction of tea consumption was seen to improve symptoms for patients. The authors concluded that $\mathrm{F}$ excess should be considered in all patients with a history of excessive tea consumption, especially due to its insidious nature and nonspecific clinical presentation [129].

Isbell and Villareal-Armamento (2010) reported the case of a 45-year-old US male diagnosed with skeletal fluorosis from ingesting $1.87 \mathrm{~L}$ of instant tea daily for $10-15$ years [211]. Plasma F levels were reported to be $7 \mu \mathrm{mol} / \mathrm{L}$. Radiographic findings showed that bone mineral density was above the expected range; however, the bones were more brittle and susceptible to fracture [211]. In another USA study, Izuora et al. (2011) reported a case study of a 48-year-old woman with abnormal bone mineral density who suffered severe chronic bone and joint pain and kyphosis (abnormal curvature of the thoracic spine) from excessive consumption of tea over a period of three decades [212]. Painful areas included her elbows, wrists, hips, knees, and ankles. The patient consumed at least $3.8 \mathrm{~L}$ of tea daily containing $1.59 \mathrm{mg} / \mathrm{L}$ of $\mathrm{F}$, as measured by ion-specific electrode. Serum F levels were $11.5 \mu \mathrm{mol} / \mathrm{L}$ and $24 \mathrm{hr}$ urinary $\mathrm{F}$ excretion was $12.5 \mathrm{mg}$ a day. A lateral radiograph of the spine indicated crippling skeletal fluorosis from severe calcification, osteoporosis, and increased bone density. Treatment was provided by avoiding all $\mathrm{F}$ in the diet and administering vitamin $\mathrm{D}$ and calcium. Six months after cessation of tea drinking, the patient reported nearly complete resolution of her pains [212]. As previously mentioned, Kakumanu and Rao (2013) reported a case study of a 47-year-old American woman who developed severe pain in lower back, arms, legs, and hips and had all her teeth extracted due to brittleness from excessive tea drinking over a period of 17 years. Serum F levels were measured at $23 \mu \mathrm{mol} / \mathrm{L}$. After discontinuation of tea consumption, her symptoms improved [157].

In France, Hayem et al. (2004) identified 5 patients in their practice in Paris, who developed skeletal fluorosis as a consequence of drinking 0.75 to 2 litres per day of tea over a course of 10 to 25 years [213]. The skeletal fluorosis in these patients was the osteomalacic variety of the disease, in which the bones become softened and weak. As a result of the "F-related osteomalacia," the patients suffered "spontaneous bone fractures" where their bones fractured without external trauma. Plasma F levels measured two days after the patients' last cup of tea (and thus do not reflect the peak F levels) were $3.9 \mu \mathrm{mol} / \mathrm{L}$. The authors concluded that heavy and prolonged consumption of tea may be capable of inducing Frelated osteomalacia manifesting as unexpected spontaneous bone fractures [213]. Notably, Inkovaara et al. (1975) recommended that ionic plasma $\mathrm{F}$ concentrations should not exceed $3 \mu \mathrm{mol} / \mathrm{L}$ to reduce the risk of bone fractures in person over 65 years of age [214].

The findings of an intriguing study published by Kurland et al. (2007) regarding a patient who developed skeletal fluorosis from excessive tooth brushing (six times a day) using fluoridated toothpaste are also worth noting [215]. This case is especially significant as the patient, a 52-year-old white American male, did not reside in a fluoridated community and had no known occupational or environmental exposure to F apart from toothpaste. Analysis of the patient's drinking water sources, including tap water (from a well) and bottled water, showed no detectable F. There was no exposure to mining, welding, or industrial use of hydrofluoric acid, nor exposure to $\mathrm{F}$ containing insecticides, niflumic acid, or laundry powders. He stated that he did not swallow toothpaste, used nonfluoridated mouthwash, had semiannual dental visits, but without $\mathrm{F}$ treatments, did not drink tea or wine, and had not chewed tobacco, inhaled snuff, or cooked with Teflon pots. Initial observations suggested ankylosing spondylitis until laboratory evaluation of blood and urine and radiological examination confirmed skeletal fluorosis. Serum $\mathrm{F}$ levels were found to range from 15 to $18.0 \mu \mathrm{mol} / \mathrm{L}$. The case uniquely charts the natural history of skeletal fluorosis 
after F exposure ceases. Within 8 months of documentation of skeletal fluorosis and after avoiding fluoridated dental products, serum $\mathrm{F}$ decreased to $<2.5 \mu \mathrm{mol} / \mathrm{L}$. Within twelve months, some improvement of joint pains and neck stiffness was evident and within two years after diagnosis and apparent elimination of excess $\mathrm{F}$ exposure, the patient had complete resolution of his neck immobility and no longer required analgesics [215]. Urinary F, bone mineral density, and bone F levels were also found to decline after removal of $\mathrm{F}$ exposure and bone health was found to improve. After a period of 8 years, bone $\mathrm{F}$ levels had declined by $36 \%$. However, the authors observed that a period of 32 years would be required before bone $\mathrm{F}$ levels would reach the normal range. While this patient did not drink tea or fluoridated water, it nevertheless highlights the contribution of fluoridated toothpaste to $\mathrm{F}$ exposure when used excessively.

In the UK, a similar case study was reported by Joshi et al. (2011), concerning a British woman of similar age who presented with a metatarsal fracture and was subsequently diagnosed with skeletal fluorosis. Radiological findings showed marked osteosclerosis of the spine and pelvis and ossification of ligaments. Serum and bone F levels were markedly elevated at $44.2 \mu \mathrm{mol} / \mathrm{L}$ and $15,144 \mathrm{mg} / \mathrm{kg}$, respectively [216]. The patient consumed $1.4 \mathrm{~L}$ of black tea daily and used toothpaste excessively, brushing her teeth eight to ten times per day. Daily F intake from tea was estimated at $10.9 \mathrm{mg}$ and $4.2 \mathrm{mg}$ from toothpaste [216]. The striking difference in serum $\mathrm{F}$ levels can be accounted for by the contribution of BT.

Previous controlled studies involving children aged 34 years have shown that plasma $\mathrm{F}$ levels can increase to $3.4 \mu \mathrm{mol} / \mathrm{L}$ after using fluoridated toothpaste containing 1000 ppm F [217]. Recently, Zohoori et al. (2015) measured fasting ionic $\mathrm{F}$ levels in nine healthy adults aged 20-35 years (5 men and 4 women) residing in a nonfluoridated community in the UK [218]. The mean baseline ionic plasma F level was reported to be $3.2 \mu \mathrm{mol} / 1$. During the experiment, subjects were provided with nonfluoride toothpaste to use for a week. After switching to a nonfluoridated toothpaste, the mean baseline plasma $\mathrm{F}$ levels were observed to reduce to $0.58 \mu \mathrm{mol} / \mathrm{L}$. The authors suggested that the high fasting plasma $\mathrm{F}$ concentration was due to brushing with a fluoridated toothpaste ( $1400 \mathrm{ppm} \mathrm{F}$ ) by participants in the morning before attending the preexperimental session [218].

To put this in context, based on the results obtained from these latter studies and those by Toyota [178], it is evident that tooth brushing with commercial fluoridated toothpaste once a day can provide an exposure greater than that associated with ingesting a cup of BT containing $1.4 \mathrm{mg}$ of fluoride. Taken together, these studies clearly highlight the effect of steady, continuous exposure to $\mathrm{F}$ and the impact of cumulative exposures.

To our knowledge, no biomonitoring studies measuring ionic $\mathrm{F}$ concentrations have been undertaken in NZ. However, in the USA, Singer and Orphaug (1979) found that mean ionic $\mathrm{F}$ in plasma in 264 fasting healthy male and female subjects of different ages who resided in a community with fluoridated water $(1 \mathrm{mg} / \mathrm{L})$ ranged from $2.74 \mu \mathrm{mol} / \mathrm{L}$ for subjects aged $10-20$ years to $3.89 \mu \mathrm{mol} / \mathrm{L}$ for subjects over 60 years [219]. For persons aged 10 to 60 years and older than 60 years the range of ionic $\mathrm{F}$ was $0.53-5.79$ and 1.05 to $6.84 \mu \mathrm{mol} / \mathrm{L}$, respectively [219]. In another USA study, Parkins et al. (1974) examined the plasma of 41 inpatients from 17 to 82 years of age (of whom 36 were currently living in an area with fluoridated water) and found a mean ionic $\mathrm{F}$ concentration of $2.46 \mu \mathrm{mol} / \mathrm{L}$ and a range of ionic $\mathrm{F}$ from 1.0 to $5.89 \mu \mathrm{mol} / \mathrm{L}$ [220]. Smiley et al. (1991) measured fasting plasma $\mathrm{F}$ levels ranging from 3.7 to $4.6 \mu \mathrm{mol} / \mathrm{L}$. in adults (mean age $45 \mathrm{yrs}$ ) residing in fluoridated communities in New York [221]. From this data, it should be pointed out that the general population in fluoridated communities in the USA, have similar or higher exposure to $\mathrm{F}$ as workers occupationally exposed to $\mathrm{F}$ at a Swedish Aluminium Plant following an eight-hour work shift [222].

Based on this evidence, the $\mathrm{F}$ levels in tea products reported in this study and the long history of habitual tea drinking in $\mathrm{NZ}$ combined with other additive sources of $\mathrm{F}$ exposure including water fluoridation; toothpaste; mouthwash; food; and medication, evidence would strongly suggest that a substantial percentage of adult NZ population would have blood F levels within the established range associated with chronic F intoxication and stage I and stage II skeletal fluorosis [208].

As Krishnamachari (1986) described, a combination of osteosclerosis, osteomalacia, and osteoporosis of varying degrees as well as exostosis formation characterizes the progression of skeletal fluorosis [223]. While F therapy has previously been used extensively in the treatment of osteoporosis, it can result in pathological changes to mineralized bone, biomechanical incompetence, and skeletal fluorosis $[224,225]$. While $\mathrm{F}$ has been found to increase bone mineral density [226], the increase in bone mass does not necessarily result in an increase in bone strength as the bone is poorly mineralized and exhibits inflammatory foci [227]. Kakei et al. (2007) demonstrated that $\mathrm{F}$ intake caused crystal structure defects in calcified hard tissues [228]. Carter and Beaupré (1990) demonstrated that the adverse influences of $\mathrm{F}$ on the mineralized bone contribute to losses in trabecular strength which can be caused by the presence of hypomineralized or hypermineralized fluorotic tissue [229]. Kakei et al. (2015) using ovariectomized rats, as an animal model of postmenopausal women, found that $\mathrm{F}$ at low concentrations $(1.0 \mathrm{mg} / \mathrm{l})$, combined with estrogen deficiency, caused crystal structure defects and accelerated osteoporotic changes in bone. Based on these findings, the authors concluded that $\mathrm{F}$ exposure increases bone fragility and may increase the risk of developing osteoporosis [230]. It is acknowledged that women over the age of 50 years become susceptible to osteoporosis because of the loss of estrogen at menopause [231].

It is further acknowledged that oxidative stress and low antioxidant status are risk factors for osteoporosis [232-234]. $\mathrm{F}$ decreases oxygen consumption and increases superoxide production in osteoblastic cells and enhances reactive oxygen species (ROS) generation in bone marrow cells [235, 236]. These results indicate that $\mathrm{F}$ can damage bone tissue by inhibiting the respiratory chain, increasing the production of superoxide radicals and thus of the other ROS [235]. Human studies have reported that when serum F levels in 
adults increased from 0.5 to $13 \mu \mathrm{mol} / \mathrm{L}$ the products of lipid peroxidation in blood increase significantly and the antioxidant activity of superoxide dismutase (SOD), catalase (CAT), and glutathione peroxidase (GPx) decreased markedly in $\mathrm{F}$ exposed individuals compared to healthy controls $[237,238]$. Dlugosz et al. (2009) demonstrated that estrogens protect against $\mathrm{F}$ induced toxicity by increasing thiol group levels which act to impair lipid peroxidation and suggested that postmenopausal women could be more sensitive to $F$ induced oxidative stress [239].

Kataraki and Rao (2012) demonstrated that serum F levels and oxidative stress biomarkers increased markedly in woman after menopause compared to nonpregnant women aged 20-40 years residing in the same area [240]. Ishiguro (1991) measured the F content in bones of men and women subjects aged 20 to 93 years and found that the F concentrations in men increased steadily with age; however, in women bone $\mathrm{F}$ concentrations increased markedly over the age of 55 years [241]. Notably, Inkovaara et al. (1975) recommended that ionic plasma $\mathrm{F}$ concentrations should not exceed $3 \mu \mathrm{mol} / \mathrm{L}$ to reduce the risk of bone fractures in person over 65 years of age [214].

In a large cohort study conducted in Finland, Kurttio et al. (1999) found that higher $F$ intake was associated with increased risk of hip fractures among women aged 50-64 years [242]. Li et al. (2001) examined the association with long-term $\mathrm{F}$ exposure and risk of bone fractures in a study group of 8266 male and female Chinese adults aged 50 years and over [243]. Parameters evaluated included F exposure, prevalence of bone fractures, demographics, medical history, physical activity, cigarette smoking, and alcohol consumption. None of the subjects used fluoridated toothpaste or mouthwash. Remarkably, only $13.5 \%$ reported tea drinking and the F content in tea brewed tea samples, though not reported, was insignificant [243]. The results confirmed that drinking water was the only major source of $F$ exposure in the study populations. The report found that the prevalence of hip fractures was highest in the group with the highest $\mathrm{F}$ intake and lowest in the group with $<1 \mathrm{mg} /$ day intake. The risk of hip fracture was twofold higher in subjects with a daily intake of $6.5 \mathrm{mg} /$ day and threefold higher with intake of $14 \mathrm{mg}$ /day compared to the lowest exposure group ( $<1 \mathrm{mg} /$ day) [243].

In the USA, Sowers et al. (1991) found an association between $\mathrm{F}$ intake, osteoporosis, and fracture of the wrist, spine, or hip with increasing F exposure [244]. Several other ecological studies have also suggested an increased risk of hip fracture associated with fluoridation [245-248]. Karagas et al. (1996) found that, for men aged 65 and 90 years living in area with fluoridated water in the USA, the relative rates of fractures of the proximal humerus and distal forearm were significantly increased (by $23 \%$ and $16 \%$, resp.) [249]. In another large USA prospective study involving 121,700 women aged 30-55 years of age, Feskanich et al. (1998) found an association between water fluoridation and risk of distal forearm fractures [250]. In a multicentre prospective study conducted in the USA, Phipps et al. (2000) found that postmenopausal women who had lived for more than 20 years in an area with fluoridated water had an increased risk for fractures of the wrist compared to those not exposed
[251]. These findings are of concern, considering the reported increase in incidence of distal forearm fracture among USA men and women under 20 years of age in recent decades [252]. Furthermore, Kim et al. (2012) reported that, compared to epidemiologic studies in Japan and European countries, the incidence rates of humerus fractures are substantially higher in the USA; for distal humerus, the peak rate of fractures was highest among children aged 5-9 years [253].

Taken together, there is a substantial body of evidence to support the view that $\mathrm{F}$ intake and water fluoridation may be associated with increased risk of osteoporotic fractures, as well as increased risk of bone fractures in the young.

4.5. Temporal Changes in Antioxidant Content in Black Tea. In reference to skeletal fluorosis from BT consumption, it is also necessary to examine how the effects of changes in tea manufacturing processes in recent decades may have altered antioxidant activity of BT products. Among the antioxidants in tea, (-)-epigallocatechin-3-gallate (EGCG) is known to be the most potent antioxidant [254]. In general, GT has been found to be superior to BT in terms of health effects, owing to the higher content of EGCG $[255,256]$. More importantly, EGCG has been shown to play a crucial role in mitigating the effects of oxidative stress induced damage by $\mathrm{F}$ on plasma, bone, and several organs such as the heart, liver, kidney, lung, testes, and brain [257-267]. Carloni et al. (2013) found that, in the manufacture of CTC black tea, a profound loss in total catechin content and antioxidant potential is observed. Most notably, the EGCG content in GT and orthodox BT was almost 50-fold higher than in CTC black tea [268]. Numerous studies have also shown that that the addition of milk to BT, which is the common practice in Western countries, has been found to further reduce the antioxidant potential of BT [269272]. An unexpected finding is that the addition of milk to GT has been found to enhance the antioxidant capacity of GTs $[273,274]$.

Based on this evidence, we hypothesise that, in addition to contributing to higher F exposure, the introduction of CTC teabags may also have contributed to profoundly reduced antioxidant intake among BT consumers, thereby increasing the risk of fluorosis related disorders. We further hypothesise that the Western practices of consuming BT with milk may contribute to a state of chronic systemic inflammation with a diminished capacity to compensate for conditions of increased oxidative stress associated with excessive F intake, as well as cumulative exposures to other environmental toxins, including aluminium and pesticide residues such as chlorpyrifos and deltamethrin, which have been shown to have synergistic toxicity with $\mathrm{F}$ [275-280].

We also hypothesise that in countries with water fluoridation and history of BT consumption the effects will be disproportionate compared to countries without water fluoridation.

4.6. Relevance to NZ Population. The most recent dietary $\mathrm{F}$ intake assessment in NZ reported that the mean dietary F intake from all sources, including food, water, beverages, and use of dental products for NZ adults ranged from 1.4 to $2.5 \mathrm{mg} /$ day in communities with fluoridated water 
and $0.8-1.3 \mathrm{mg} /$ day in nonfluoridated communities [281]. The results of this study show that, in NZ, for individuals residing in communities with fluoridated water supplies, certain popular brands of BT can contribute $4.1-5.9 \mathrm{mg} /$ day for moderate (3-4 mugs per day) and $8.8-14.7 \mathrm{mg} /$ day for heavy tea drinkers (6-10 mugs per day), respectively. Thus, regular consumption of BT can exceed the AI and UL for $\mathrm{F}$ without taking cumulative $\mathrm{F}$ exposure from other dietary sources including food, water, alcoholic beverages, use of toothpaste or F mouthwash, and tobacco consumption.

It is important to be aware that in NZ and Australia the market share of fluoridated toothpaste is reported to be $98 \%$, which is similar to the US [282]. In comparison, in the 1970 and 1980, fluoridated toothpaste represented 6\% and $76 \%$ of total toothpaste sales in NZ, respectively [79]. It is noteworthy, as previously discussed, that the prevalence of dental fluorosis in children has increased significantly in NZ since the 1980s [79-81].

It is also important to note that other sources of $\mathrm{F}$ such as tobacco are widely available in NZ. In NZ, $26 \%$ and $20 \%$ of males aged 18-34 and 35-54 years of age, respectively, currently use tobacco. For women, the percentage is $20 \%$ and $17 \%$, respectively. Notably, for Maori population, the percentage is much higher with $40 \%$ of women 15 years and older daily smokers and 35\% of men [283]. Smoking is associated with increased oxidative stress and a compromised antioxidant defence system [284] and tobacco products are known to contain high concentrations of $\mathrm{F}[98,285,286]$, which suggests synergistic interactions. Several studies have identified that the prevalence of fluorosis and severity of the disease increase with smoking [93-97], which appears to confirm this relationship. Notably, Tu et al. (2010) found that the fluoride levels in blood and urine of regular and occasional smokers were significantly higher than those of nonsmokers [94]. However, as with tea, the F content in tobacco products in NZ or the contribution of tobacco consumption to dietary $\mathrm{F}$ intake has not been assessed. Further studies are needed to quantify the F content in NZ tobacco products and synergistic interactions between $\mathrm{F}$ and other toxic heavy metals in tea and tobacco.

As previously noted, Warnakulasuriya et al. (2002) found that alcoholic beverages (beers) produced on fluoridated water supplies in the UK and Ireland can be a major contributor to $\mathrm{F}$ intake and contribute to metabolic bone disease, particularly among habitual consumers [91]. Further studies are needed to determine the F content in NZ beers and their contribution to dietary $\mathrm{F}$ intake among the adult population.

Finally, it is necessary to mention a few health statistics to measure the possible contribution of chronic fluoride exposure to overall health disability burden in NZ. As previously discussed, the most reported adverse health effects of chronic $\mathrm{F}$ intoxication are chronic pain and musculoskeletal disorders. There is compelling clinical evidence that musculoskeletal disorders and chronic pain are highly prevalent in NZ and their impact is pervasive. Arthritis is the leading cause of disability in NZ, affecting nearly 1 in 6 people [287]. In 2010, the total financial cost of arthritis in NZ was estimated to be $\$ 3.20$ billion [287]. Notably, the latest NZ Health survey found that the prevalence of chronic pain and arthritis is increasing. About 620,000 adults (17\%) had arthritis with more than half of adults aged 75 years and over (54\%) being affected. Moreover, one in five adults were found to be suffering from chronic pain [288]. The prevalence of chronic pain was also found to increase with age affecting $32 \%$ of adults aged $65-74$ years of age [288]. Swain and Johnson (2014) reported that the most common pain locations among chronic pain sufferers in NZ were lower back (59\%), pelvis/abdomen (49\%), joints (39\%), neck (34\%), muscle (31\%), and headache (31\%) [289]. Notably, Dominick et al. (2011) found that the prevalence of chronic pain was twice as high in New Zealanders of European and Maori ethnicity compared to New Zealanders of Asian ethnicity [290]. This may indicate the preference of GT as the choice of tea beverage among Asians or other genetic factors [291294].

However, the burden of headaches, migraine, and osteoporosis is also high in NZ. Thomson et al. (1993) reported that the prevalence of bad headaches among adults in NZ was $40.6 \%$ with $54.5 \%$ of these having the characteristics of bad headache with features symptomatic of migraine [295]. In 2007 , it was estimated that over 70,000 men and women were diagnosed with osteoporosis and over 84,000 osteoporotic fractures occurred, costing the NZ economy over $\$ 1.15$ billion per year. By 2020, it has been reported that NZ can expect nearly 116,000 fractures directly attributable to osteoporosis each year [296].

It is also necessary to mention the burden of chronic kidney disease and diabetes in NZ. Coppell et al. (2013) reported that prevalence of prediabetes among New Zealanders aged 15 years and over was $25.5 \%$ with an overall prevalence of diabetes of 7.0\% [297]. The prevalence of diagnosed diabetes was found to increase significantly with age affecting 1 in 4 men over 75 and 1 in 8 women, respectively. Prevalence rates among both Maori and Pacific islanders were more than double those of NZ Europeans [297].

Chronic kidney disease and diabetes are characterized by abnormally low glomerular filtration rate [298]. Individuals with kidney disease have decreased ability to excrete $\mathrm{F}$ in urine and are at risk of developing fluorosis even at normal recommended limit of $\mathrm{F}$ in drinking water $[187,299]$. It is well established that that circulating F levels can be 3 to 5 times higher in subjects with renal insufficiency compared to healthy controls [300-302]. Age-associated loss of kidney function has also been recognized for decades [303, 304]. With aging, many subjects exhibit progressive decreases in glomerular filtration rate, which results in increased retention of $\mathrm{F}$ causing higher plasma $\mathrm{F}$ levels. It has been further suggested that this decreased clearance of $\mathrm{F}$ may indicate that elderly people are more susceptible to $\mathrm{F}$ toxicity $[2,305]$. $\mathrm{NZ}$ is currently experiencing a dramatic increase in its older adult population as part of a global aging phenomenon. With this, NZ rapidly aging population ( $\geq 65$ years of age) is set to increase by $84 \%$ between the years 2006 and 2026 [306].

It is important to also note that the NRC (2006) reported that the intake of $\mathrm{F}$ for individuals with low iodine status poses significantly higher risk of negative outcomes than for healthy individuals [2]. Recent evidence from a number of 
studies has indicated the reemergence in iodine deficiency in NZ among both children and adults [307-309].

Taken together, a substantial body of evidence, namely, the history of habitual BT consumption and other dietary sources of $\mathrm{F}$ combined with a rapidly aging population, the reemergence in iodine deficiency, prevalence of smoking, and prediabetes and diabetes, suggests that a substantial portion of the adult population in NZ are at high risk of developing skeletal fluorosis.

\section{Limitations of the Study}

No study is without limitations, and it is important to provide some perspective in this context. The objective of this study was to determine the F content in tea infusions and access the range of likely human exposures to F from BT consumption in NZ. However, without biomonitoring of the population, measuring bone, and plasma $\mathrm{F}$ levels and without studies examining the direct association between $\mathrm{F}$ intake and its possible relationship to chronic inflammatory diseases in $\mathrm{NZ}$, the association between $\mathrm{F}$ intake and chronic morbidity cannot reliably be shown to be causal. Therefore, it is not possible to make conclusive statements about the association without further research to confirm the above suggestions. This field of research would therefore benefit from prospective or longitudinal studies assessing associations between $\mathrm{F}$ intake, cumulative $\mathrm{F}$ exposure, total body burden of $\mathrm{F}$, and the impact of long-term chronic F exposure on the health of older adults.

There are other limitations such as seasonal variation in $\mathrm{F}$ content in BT products, pesticide, heavy metal, and polyphenol (EGCG) contents which were not determined. Pesticides residues in tea can be transferred into tea infusion and then consumed by humans [310]. As previously noted, it has also been found that coexposure to $\mathrm{F}$ and aluminium or pesticides, such as CPF, results in synergistic interactions and enhanced toxicity [275-280]. Bishnu et al. (2009) reported that CPF pesticide residues have been found in tea at concentrations that may pose health hazards to the consumers [311]. High aluminium concentrations in tea infusions have also been found to result in underrepresentation of $F$ levels in tea infusions when measured by ISE method [312, 313]. However, it should be noted that no funding was provided to undertake this study and the aim of the study was to solely measure the ionic F levels in tea. Moreover, our review of published literature found that the aluminium content in tea infusions is generally never reported when measuring the $\mathrm{F}$ content in tea infusions.

A further limitation of this study is that we did not include an exposure assessment for $\mathrm{F}$ intake from tea for children or adolescents or discuss other potential nonskeletal effects of $\mathrm{F}$ such as endocrine dysfunction, cardiotoxicity, pulmonary toxicity, or neurotoxicity in our review of health impacts, as this would require further research beyond the scope and limitations of this study. Nonetheless, limitations should not be construed as detracting from the message of the paper; rather, they are the type of limitations indicating that further work needs to be done to establish causality. We also opine that this study and our review of published literature represents the most comprehensive summary of the effects of $\mathrm{F}$ on the skeletal system and includes solid evidence of a potential causative association between environmental exposure to $\mathrm{F}$ and chronic inflammatory disease.

The need to combine clinical and epidemiological strategies to address long-term $F$ accumulation in the adult population may seem obvious, but it is often overlooked in Western countries. The apparent lack of clinical diagnoses of skeletal fluorosis in Western countries may stem from differences in diagnostic practices, which are well established for skeletal fluorosis in Asian countries, due to the fact that skeletal fluorosis is a major public health burden in India and China. Notably, in China, clinicians are also experienced in investigating skeletal fluorosis from tea, due to the culture of tea drinking in China. However, diagnosis of skeletal fluorosis from tea drinking in Western countries is a relatively new phenomenon and largely coincides with the introduction and market dominance of CTC teabags.

Interestingly, in recent years, most studies in Western countries have come from the USA, which has one of the lowest per capita consumption rates of tea internationally, far below that of NZ, Australia, or the RoI, and which also practices water fluoridation as do NZ, Australia, and the RoI. Yet remarkably, we are not aware of any published information documenting skeletal fluorosis from tea in these latter countries.

\section{Conclusion}

The main finding of this study is that tea is an important and underrepresented source of exposure to F in NZ. In our study, we have demonstrated that the potential $\mathrm{F}$ intake from BT consumption is much higher than previously recognized in NZ. Moreover, evidence suggests that the culture of tea drinking in NZ contributes significantly to the total body burden of $\mathrm{F}$ among New Zealanders. Although specified regulations concerning tea quality are well established internationally, the $\mathrm{F}$ content in tea products is not included. Producers of tea products should label the F concentration of their products. Such labelling will allow consumers to make informed decisions and dentists, dental hygienists, and other healthcare professionals to appropriately advise patients regarding $\mathrm{F}$ intake and use of fluoride products. Because $\mathrm{F}$ toothpastes and other oral healthcare products such as $\mathrm{F}$ mouth rinses are widely available, the cumulative exposure from various combinations of $\mathrm{F}$ modalities can result in excessive cumulative exposures. In this study, we have presented a potential causal relationship between cumulative $\mathrm{F}$ intake, chronic pain, musculoskeletal disorders, arthritic diseases, and osteoporotic fractures and its relevance to NZ. Based on our observations and hypothesis, the substantial amounts of $\mathrm{F}$ found in commercial tea brands in this study, and the long history of BT drinking in NZ, combined with other risk factors such as water fluoridation, alcohol consumption, smoking, and diabetes, it is evident that a sizable portion of the NZ population are susceptible to the health risks associated with long-term chronic F intake. Further studies are needed to confirm this association. Taken together, our study illustrates that there is a considerable gap in 
knowledge and in recognizing and identifying key risk factors that influence policy making decisions surrounding water fluoridation. On the basis of credible evaluations of public health policy, adequate evidence based surveillance systems must be put in place to monitor the variety and sources of environmental exposure to fluoride, including cumulative impacts and synergistic interactions. Such studies need to determine individuals bone and plasma $\mathrm{F}$ levels in addition to other molecular biomarkers. In addition, risk factors and behaviours that may be linked to increased susceptibility to fluoride intoxication must also be adequately examined, such as smoking, alcohol consumption, diabetes, nutritional and endocrine disorders, iodine deficiency, gender, age, and genetic susceptibility.

\section{Abbreviations}

$\begin{array}{ll}\text { AI: } & \text { Adequate Intake } \\ \text { BT: } & \text { Black tea } \\ \text { CPF: } & \text { Chlorpyrifos } \\ \text { DRVs: } & \text { Dietary reference values } \\ \text { EU: } & \text { European Union } \\ \text { EFSA: } & \text { European Food Safety Authority } \\ \text { F: } & \text { Fluoride } \\ \text { GT: } & \text { Green tea } \\ \text { NRC: } & \text { National Research Council } \\ \text { NZ: } & \text { New Zealand } \\ \text { RoI: } & \text { Republic of Ireland } \\ \text { RME: } & \text { Reasonable maximum exposure } \\ \text { SCHER: } & \text { Scientific Committee on Health and } \\ & \text { Environmental Risks } \\ \text { TISAB: } & \text { Total ionic strength adjustment buffer } \\ \text { UK: } & \text { United Kingdom } \\ \text { UL: } & \text { Tolerable Upper Intake Level } \\ \text { USA: } & \text { United States of America } \\ \text { WHO: } & \text { World Health Organization. }\end{array}$

\section{Conflicts of Interest}

Declan T. Waugh works as a Freelancer in the field of environmental science, due diligence, and risk assessment. Michael Godfrey is an Independent Medical Practitioner and Director of BOP Environmental Health and past President of the NZ Academy of Oral Medicine and Toxicology. Hardy Limeback is Professor Emeritus and Former Head of Preventive Dentistry, Faculty of Dentistry, University of Toronto, Canada, and Former Member of the US National Research Council Scientific Committee on Fluoride in Drinking Water. William Potter is Professor of Chemistry and Biochemistry at University of Tulsa, OK, USA. None of the authors received payment or benefit for this work. This work was undertaken without funding for the benefit of public health and the advancement of scientific education in the fields of health promotion and disease prevention. The authors declare they have no conflicts of interest.

\section{Authors' Contributions}

Declan T. Waugh contributed to the study conception, performed all the analyses, drafted the manuscript, and oversaw coordination of this study. Michael Godfrey purchased the tea products. Michael Godfrey, William Potter, and Hardy Limeback contributed to interpretation of results, intellectual content, literature review, and manuscript revisions. All authors reviewed and approved the final manuscript.

\section{References}

[1] A. Beresniak, G. Duru, G. Berger, and D. Bremond-Gignac, "Relationships between black tea consumption and key health indicators in the world: An ecological study," BMJ Open, vol. 2, no. 6, Article ID e000648, 2012.

[2] United States National Research Council, Review of Fluoride in Drinking Water, United States National Research Council, 2006.

[3] Fluorides and Human Health, 59, World Health Organization, Geneva, Switzerland, 1970, Monograph.

[4] C. B. Walters, J. C. Sherlock, W. H. Evans, and J. I. Read, "Dietary intake of fluoride in the united kingdom and fluoride content of some foodstuffs," Journal of the Science of Food and Agriculture, vol. 34, no. 5, pp. 523-528, 1983.

[5] J. Cao, Y. Zhao, Y. Li, H. J. Deng, J. Yi, and J. W. Liu, "Fluoride levels in various black tea commodities: measurement and safety evaluation," Food and Chemical Toxicology, vol. 44, no. 7, pp. 1131-1137, 2006.

[6] E. Malinowska, I. Inkielewicz, W. Czarnowski, and P. Szefer, "Assessment of fluoride concentration and daily intake by human from tea and herbal infusions," Food and Chemical Toxicology, vol. 46, no. 3, pp. 1055-1061, 2008.

[7] A. Koblar, G. Tavčar, and M. Ponikvar-Svet, "Fluoride in teas of different types and forms and the exposure of humans to fluoride with tea and diet," Food Chemistry, vol. 130, no. 2, pp. 286-290, 2012.

[8] L. Chan, A. Mehra, S. Saikat, and P. Lynch, "Human exposure assessment of fluoride from tea (Camellia sinensis L.): A UK based issue?" Food Research International, vol. 51, no. 2, pp. 564570,2013

[9] S. C. Lung, H. Cheng, and C. B. Fu, "Potential exposure and risk of fluoride intakes from tea drinks produced in Taiwan," Journal of Exposure Science and Environmental Epidemiology, vol. 18, no. 2, pp. 158-166, 2008.

[10] D. T. Waugh, W. Potter, H. Limeback, and M. Godfrey, "Risk assessment of fluoride intake from tea in the republic of ireland and its implications for public health and water fluoridation," International Journal of Environmental Research and Public Health, vol. 13, no. 3, article no. 259, 2016.

[11] J. Gershon-Cohen and J. F. McClendon, "The cariostatic effect of flourine in tea," J Albert Einstein Med Cent (Phila), vol. 5, no. 2, pp. 153-154, 1957.

[12] A. C. Ramsey, J. Hardwick, and J. C. Tamacas, "Fluoride intakes and caries increments in relation to tea consumption by British Children. (abstract) 21st ORCA Congress," in Proceedings of the, London, UK, 1974.

[13] R. L. Speirs, "Correlations between the concentrations of fluoride and some other constituents in tea infusions and their possible dental caries-preventive effect," Archives of Oral Biology, vol. 28, no. 6, pp. 471-475, 1983.

[14] P. Goenka, A. Sarawgi, V. Karun, A. Nigam, S. Dutta, and N. Marwah, "Camellia sinensis (Tea): Implications and role in preventing dental decay," Pharmacognosy Reviews, vol. 7, no. 14, pp. 152-156, 2013. 
[15] M. Elvin-Lewis and R. Steelman, "The anticariogenic effects of tea drinking among Dallas school children," Journal of Dental Research, pp. 65-198, 1986.

[16] J. M. T. Hamilton-Miller, "Anti-cariogenic properties of tea (Camellia sinensis)," Journal of Medical Microbiology, vol. 50, pp. 299-302, 2001.

[17] A. C. Ramsey, J. Hardwick, and J. C. Tamacas, "Fluoride intakes and caries increments in relation to tea consumption," Caries Research, vol. 9, p. 312, 1975.

[18] M. Onisi, M. Kosuge, F. Yoshino, and Y. Murakami, "Epidemiological evidence about the caries preventive effect of drinking tea," The Journal of Preventive Dentistry, vol. 6, pp. 321-325, 1980.

[19] M. Onishi, N. Shimura, C. Nakamura, and M. Sato, "A field test on the caries preventive effect of tea drinking," Journal of Dental Health, vol. 31, pp. 13-19, 1981.

[20] M. Friedman, S. Solouki, S. Gurevitz, I. Gedalia, and M. Onisi, "Fluoride concentrations in tea. Its uptake by hydroxyapatite and effect on dissolution rate," Clinical preventive dentistry, pp. 6-20, 1984.

[21] M. Elvin-Lewis and R. Steelman, "The anticariogenic effects of tea drinking among Dallas school children," Journal Dental Research, pp. 65-198, 1986.

[22] C. Fraysse, W. Bilbeissi, L. Benamghar, and B. Kerebel, "Comparison of the dental health status of 8 to 14-year-old children in France and in Jordan, a country of endemic fluorisis," Bull. Group Int. Rech. Sci. Stomatol. et Odontol, pp. 169-175, 1989.

[23] P. B. Srinidhi, S. Basha, P. N. Kumar, G. M. Prashant, V. H. Sushanth, and M. Imranulla, "Effect of two different commercially available tea products on salivary $\mathrm{pH}$ : a randomized double blinded concurrent parallel study," Dentistry and Medical Research, vol. 2, no. 2, pp. 39-42, 2014.

[24] M. Onisi, F. Okumura, and Y. Murakami, "In vitro screening of tea leaves effective against dental caries," Journal of Dental Health, vol. 27, no. 4, pp. 279-287, 1978.

[25] C. C. Guarnizo-Herreño, G. Tsakos, A. Sheiham, M. G. Marmot, I. Kawachi, and R. G. Watt, "Austin Powers bites back: a cross sectional comparison of US and English national oral health surveys," BMJ, vol. 351, Article ID h6543, 2015.

[26] M. Matsumoto, T. Minami, H. Sasaki, S. Sobue, S. Hamada, and T. Ooshima, "Inhibitory effects of oolong tea extract on cariesinducing properties of mutans streptococci," Caries Research, vol. 33, pp. 441-445, 1999.

[27] H. Yu, T. Oho, and L. X. Xu, "Effects of several tea components on acid resistance of human tooth enamel," Journal of Dentistry, vol. 23, no. 2, pp. 101-105, 1995.

[28] E. Reid, "The fluorine content of some Chinese food materials," Chinese Journal of Physiology, vol. 10, pp. 259-272, 1936.

[29] H. C. Lockwood, "Fluorine in food products," The Analyst, vol. 62, no. 740, pp. 775-783, 1937.

[30] D. Jackson and S. M. Weidmann, "Fluorine in human bone related to age and the water supply of different regions," The Journal of Pathology and Bacteriology, vol. 86, no. 2, pp. 451-459, 1958.

[31] H. A. Azar, C. K. Nucho, S. I. Bayyuk, and W. B. Bayyuk, "Skeletal sclerosis due to chronic fluoride intoxication," Annals of Internal Medicine, vol. 55, pp. 193-200, 1961.

[32] S. C. Lung, H. W. Cheng, and C. B. Fu, "Potential exposure and risk of fluoride intakes from tea drinks produced in Taiwan," Journal of Exposure Science and Environmental Epidemiology, vol. 18, no. 2, pp. 158-166, 2008.
[33] "22nd Australian Total Diet Study, Food Standards Australia New Zealand. 2008," http://www.foodstandards.gov.au/ publications/documents/ATDS_App8.pdf. (accessed on 1 Nov 2016).

[34] A. M. Abd El-Atya, J. H. Choi, M. M. Rahman, S. W. Kim et al., Residues and contaminants in tea and tea infusions: a review, vol. 31, Food AddContam: Part A, 2014.

[35] J. Q. Sha and D. W. Zheng, "Study on the fluorine content in fresh leaves of tea planted in Fujian Province," Journal of Tea Science, vol. 14, pp. 37-42, 1994.

[36] J. Ruan and M. H. Wong, "Accumulation of fluoride and aluminium related to different varieties of tea plant," Environmental Geochemistry and Health, vol. 23, no. 1, pp. 53-63, 2001.

[37] H. Horie, T. Nagata, T. Mukai, T. Goto, and T. Nagata, "Determination of the chemical form of fluorine in tea infusions by 19 F-Nmr," Bioscience, Biotechnology and Biochemistry, vol. 56, no. 9, pp. 1474-1475, 1992.

[38] IARC, "IARC monographs on the evaluation of carcinogenic risks to humans, coffee, tea, mate, methylxnthines and methylglyoxal," vol. 51, pp. 207-212, Lyon, France, 1991.

[39] R. S. Bruno, J. A. Bomser, and M. G. Ferruzzi, "Processing and impact on antioxidants," in Beverages, V. R. Preedy, Ed., Academic Press, Elsevier, Oxford, UK, 2014.

[40] H. N. Graham, "Tea; the plant and its manufacture; chemistry and consumption of the beverage," in The Methylxnthine Beverages and Foods: Chemistry, Consumption and Health Effects, G. A. Spiller, Ed., pp. 29-74, Alan R. Liss, New York, NY, USA, 1984.

[41] M. Serafini, D. Del Rio, D. N. Yao, S. Bettuzzi, and I. Peluso, "Health benefits of tea," in Herbal Medicine: Biomolecular and Clinical Aspects, I. F. F. Benzie and S. Wachtel-Galor, Eds., Boca Raton (FL): CRC Press/Taylor and Francis, 2nd edition, 2011, https://www.ncbi.nlm.nih.gov/books/NBK92768/.

[42] M. Groosman, "Sector Overview, Tea. The Sustainable Trade Initiative," October 2011, http://www.bibalex.org/Search4Dev/ files//460374.pdf.

[43] V. K. Sharma, A. Bhattacharya, A. Kumar, and H. K. Sharma, "Health Benefits of Tea Consumption," Tropical Journal of Pharmaceutical Research, vol. 6, no. 3, pp. 785-792, 2007.

[44] J. T. Mao, "White tea: the plants, processing, manufacturing, and potential health benefits," in Tea in Health and Disease Prevention, V. R. Preedy, Ed., pp. 33-40, Academic Press, Elsevier, London, UK, 2013.

[45] R. S. Bruno, J. A. Bomser, and M. G. Ferruzzi, "Processing and impact on antioxidants," in Beverages, Beverages., Ed., Academic Press, Elsevier, Oxford, UK, 2014.

[46] T. Ming, "A revision of Camellia sect," Thea Acta Botanica Yunnanica, vol. 14, no. 2, pp. 115-132, 1992.

[47] M. C. Wambulwa, M. K. Meegahakumbura, S. Kamunya, A. Muchugi et al., "Insights into the genetic relationships and breeding patterns of the African tea germplasm based on nSSR markers and cpDNA sequences," Frontiers in Plant Science, vol. 7, no. article, 1244, 2016.

[48] N. Khan and H. Mukhtar, "Tea and health: studies in humans," Current Pharmaceutical Design, vol. 19, no. 34, pp. 6141-6147, 2013.

[49] D. Grigg, "The worlds of tea and coffee: Patterns of consumption," GeoJournal, vol. 57, no. 4, pp. 283-294, 2002.

[50] "Tea Fact Sheet 2016-1017. Tea Association of the U.S.A Inc," http://www.teausa.com/14655/tea-fact-sheet. 
[51] C. Someswararao and P. P. Srivastav, "A novel technology for production of instant tea powder from the existing black tea manufacturing process," Innovative Food Science and Emerging Technologies, vol. 16, pp. 143-147, 2012.

[52] F. W. Clements, A History of Human Nutrition in Australia, Longman Cheshire, Melbourne, Australia, 1986.

[53] P. Stocks, "Cancer mortality in relation to national consumption of cigarettes, solid fuel, tea and coffee," British Journal of Cancer, vol. 24, no. 2, pp. 215-225, 1970.

[54] P. Feetham, The Positioning of Premium Private Label Brands. Thesis for the degree of Master of Business Studies in Marketing at Massey University, Massey University, Palmerston North, New Zealand, 2011, http://mro.massey.ac.nz/bitstream/handle/ 10179/3342/02_whole.pdf.

[55] C. M. Nagle, C. M. Olsen, C. J. Bain, D. C. Whiteman, A. C. Green, and P. M. Webb, "Tea consumption and risk of ovarian cancer," Cancer Causes and Control, vol. 21, no. 9, pp. 1485-1491, 2010.

[56] Y. J. Song, A. R. Kristal, K. G. Wicklund, K. L. CushingHaugen, and M. A. Rossing, "Coffee, tea, colas, and risk of epithelial ovarian cancer," Cancer Epidemiology Biomarkers and Prevention, vol. 17, no. 3, pp. 712-716, 2008.

[57] "Beverage Choices of U.S. Adults, What We Eat in America, NHANES 2007-2008. Food Surveys Research Group, Dietary Data Brief No. 6, August 2011," https://www.ars.usda.gov/ARSUserFiles/80400530/pdf/DBrief/6_beverage_choices_adults_ 0708.pdf.

[58] "United States Environmental Protection Agency., Pesticides, Registration Review. EPA Proposes to Withdraw Sulfuryl Fluoride Tolerances," https://archive.epa.gov/oppsrrd1/registration review/web/html/evaluations.html.

[59] "United States National Centre for Chronic Disease Prevention and Health Promotion, Fluoridation Growth, by Population, United States Oral Health Resources," http://www.cdc.gov/ nohss/fsgrowth_text.htm.

[60] "United States Centers for Disease Control and Prevention. Water Fluoridation," http://www.cdc.gov/fluoridation/ statistics/2012stats.htm.

[61] Fluoride Recommendations Work Group, "Recommendations for using fluoride to prevent and control dental caries in the United States," Morbidity and Mortality Weekly Report (MMWR), vol. 50, no. RR-14, pp. 1-42, 2001.

[62] United States Environmental Protection Agency, Fluoride: Exposure And Relative Source Contribution Analysis. Washington: EPA, Office of Water, Health and Ecological Criteria Division, 2010, https://www.epa.gov/dwstandardsregulations/ fluoride-risk-assessment-and-relative-source-contribution.

[63] S. Kettler, M. Kennedy, C. McNamara et al., "Assessing and reporting uncertainties in dietary exposure analysis. Mapping of uncertainties in a tiered approach.", Food and Chemical Toxicology, vol. 82, pp. 79-95, 2015.

[64] Committee on Decision Making Under Uncertainty, Board on Population Health and Public Health Practice, and Institute of Medicine, Environmental Decisions in the Face of Uncertainty, National Academies Press (US), Washington, DC, USA, 2013, Risk Assessment and Uncertainty. https://www.ncbi.nlm.nih .gov/books/NBK200844/.

[65] United States Department of Health and Human Services, "Press release. HHS issues final recommendation for community water fluoridation," 2015. http://www.hhs.gov/news/press/ 2015pres/04/20150427a.html.
[66] B. F. Gooch, "U.S. public health service recommendation for fluoride concentration in drinking water for the prevention of dental caries," Public Health Reports, vol. 130, no. 4, pp. 318-331, 2015.

[67] H. F. Akers, "Collaboration, vision and reality: water fluoridation in New Zealand (1952-1968)," New Zealand Dental Journal, vol. 104, no. 4, pp. 127-133, 2008, Commission of Inquiry 1957 Fluoridation of Public Water Supplies (Government Printer, Wellington, 1962) at 142-143.

[68] M. F. Harrison, "Fluorine Content of Teas Consumed in New Zealand," British Journal of Nutrition, vol. 3, no. 2-3, pp. 162$166,1949$.

[69] "New Zealand Ministry of Health, Fluoridation History," http://www.health.govt.nz/our-work/preventative-health-wellness/fluoridation/water-fluoridation/fluoridation-history.

[70] "New Zealand Parliament, Attachment for written Parliamentary Question 7173 (2006)," http://www.parliament.nz/ resource/0000068434.

[71] "New Zealand Ministry of Health. Drinking-water Standards for New Zealand 2005. Wellington: Ministry of Health," http:// www.health.govt.nz/publication/drinking-water-standardsnew-zealand-2005-revised-2008-0.

[72] "Food Standards Australia New Zealand. Fluoride in Packaged Water. April 2012," https://www.foodstandards.gov.au/code/ applications/documents/A1043\%20SD3.pdf.

[73] D. Moore and M. Poynton, "Review of the benefits and costs of water fluoridation in New Zealand. Report prepared for the Ministry of Health, Sapere Research Group. September 2015," https://www.health.govt.nz/system/files/documents/publications/review-benefits-costs-water-fluoridation-new-zealandapr16.pdf.

[74] J. Colquhoun, "Child dental health differences in new zealand," Community Health Studies, vol. 11, no. 2, pp. 85-90, 1987.

[75] "Ministry of Health. 2015: Age 5 and Year 8 oral health data from the Community Oral Health Service," http://www.health.govt .nz/nz-health-statistics/health-statistics-and-data-sets/oralhealth-data-and-stats/age-5-and-year-8-oral-health-data-community-oral-health-service.

[76] "New Zealand Ministry of Health. Proposed legislative changes: decision-making on the fluoridation of drinking-water supplies," http://www.health.govt.nz/our-work/preventative-health -wellness/fluoridation/proposed-legislative-changes-decisionmaking-fluoridation-drinking-water-supplies.

[77] J. Kumpulainen and P. Koivistoinen, "Fluorine in foods," in Residues of Pesticides and Other Contaminants in the Total Environment, Residue Reviews, A. F. Gunther, Ed., vol. 68, Springer, New York, NY, USA, 1977.

[78] P. Cressey, "Dietary fluoride intake for fully formula-fed infants in New Zealand: Impact of formula and water fluoride," Journal of Public Health Dentistry, vol. 70, no. 4, pp. 285-291, 2010.

[79] J. Colquhoun, "Disfiguring dental fluorosis in Auckland, New Zealand," Fluoride, vol. 17, no. 4, pp. 234-242, 1984.

[80] T. D. Mackay and W. M. Thomson, "Enamel defects and dental caries among Southland children," New Zealand Dental Journal, vol. 101, no. 2, pp. 35-43, 2005.

[81] "Ministry of Health. Our oral health: key findings of the 2009 New Zealand Oral Health Survey. Wellington: Ministry of Health; 2010," http://www.health.govt.nz/publication/ our-oral-health-key-findings-2009-new-zealand-oral-healthsurvey. 
[82] K. Pradhan, N. Arora, A. Jena, A. Susheela, and M. Bhan, "Safety of ciprofloxacin therapy in children: magnetic resonance images, body fluid levels of fluoride and linear growth," Acta Poediatrica, vol. 84, no. 5, pp. 555-560, 1995.

[83] J. L. Skiles, E. A. Imel, J. C. Christenson, J. E. Bell, and M. L. Hulbert, "Fluorosis because of prolonged voriconazole therapy in a teenager with acute myelogenous leukemia," Journal of Clinical Oncology, vol. 29, no. 32, pp. e779-e782, 2011.

[84] R. Martino, A. Lopez, M. C. Malet-Martino, J. Bernadou et al., "Release of fluoride ion from 5'-deoxy-5-fluorouridine, an antineoplastic fluoropyrimidine, in humans," Drug Metabolism and Disposition, vol. 13, pp. 116-118, 1985.

[85] C. Rimoli, C. N. Carducci, C. Dabas, C. Vescina et al., "Relationship between serum concentrations of flecainide and fluoride in humans," Bollettino Chimico Farmaceutico, vol. 130, pp. 279282, 1991.

[86] H. L. Boiteau, A. Prost, F. Rossel-Renac, M. Audran et al., "Ionized fluorine in the plasma and urine of subjects treated with organofluorine drugs prescribed in rheumatology," Revue Du Rhumatisme Et Des Maladies Osteo-Articulaires, vol. 46, no. 2, pp. 123-132, 1979.

[87] P. J. Meunier, P. Courpron, J. S. Smoller, and D. Briancon, "Niflumic acid-induced skeletal fluorosis: iatrogenic disease or therapeutic perspective for osteoporosis?" Clinical Orthopaedics and Related Research, vol. 148, pp. 304-309, 1980.

[88] H. Jewell, J. L. Maggs, A. C. Harrison, P. M. O’neill, J. E. Ruscoe, and B. K. Park, "Role of hepatic metabolism in the bioactivation and detoxication of amodiaquine," Xenobiotica, vol. 25, no. 2, pp. 199-217, 1995.

[89] T. Sassa, T. Suhara, H. Ikehira et al., "19F-magnetic resonance spectroscopy and chemical shift imaging for schizophrenic patients using haloperidol decanoate," Psychiatry and Clinical Neurosciences, vol. 56, no. 6, pp. 637-642, 2002.

[90] C. A. Full and F. M. Parkins, "Effect of cooking vessel composition on fluoride," Journal of Dental Research, vol. 54, no. 1, p. 192, 1975.

[91] S. Warnakulasuriya, C. Harris, S. Gelbier, J. Keating, and T. Peters, "Fluoride content of alcoholic beverages," Clinica Chimica Acta, vol. 320, no. 1-2, pp. 1-4, 2002.

[92] "The United States Department of Agriculture (USDA), National Fluoride Database of Selected Beverages and Foods, Release 2, December 2005," http://www.ars.usda.gov/SP2UserFiles/Place/12354500/Data/Fluoride/F02.pdf.

[93] A. Khandare, K. Rasaputra, I. Meshram, and S. Rao, "Effects of smoking, use of aluminium utensils, and tamarind consumption on fluorosis in a fluorotic village of Andhra Pradesh, India," Fluoride, vol. 43, no. 2, pp. 148-153, 2010.

[94] J. Tu, K. Liu, M. Li, Y. Zhang et al., "Study on fluorine levels in blood and urine and their correlation factors in occupational population exposed to fluoride," Chinese Journal of Industrial Medicine, vol. 03, 2010, http://en.cnki.com.cn/Article_en/ CJFDTOTAL-SOLE201003003.htm.

[95] J. Hussain, I. Hussain, and K. C. Sharma, "Fluoride and health hazards: Community perception in a fluorotic area of central Rajasthan (India): An arid environment," Environmental Monitoring and Assessment, vol. 162, no. 1-4, pp. 1-14, 2010.

[96] J. John, M. Hariharan, V. Remy, and S. Haleem, "Prevalence of skeletal fluorosis in fishermen from the Kutch Coast, Gujarat, India," Roczniki Państwowego Zakładu Higieny, vol. 66, no. 4, pp. 379-382, 2015.
[97] M. O. Tonguc, Y. Ozat, T. Sert, Y. Sonmez, and F. Y. Kirzioglu, "Tooth sensitivity in fluorotic teeth," European Journal of Dentistry, vol. 5, no. 3, pp. 273-280, 2011.

[98] M. A. Gondal, Y. B. Habibullah, L. E. Oloore, and M. A. Iqbal, "Determination of carcinogenic fluorine in cigarettes using pulsed UV laser-induced breakdown spectroscopy," Applied Optics, vol. 54, no. 17, pp. 5560-5567, 2015.

[99] N. D. Kim, M. D. Taylor, and J. J. Drewry, "Anthropogenic fluorine accumulation in the Waikato and Bay of Plenty regions of New Zealand: comparison of field data with projections," Environmental Earth Sciences, vol. 75, no. 2, article 147, pp. 1-15, 2016.

[100] R. Szostek, Z. Ciećko, M. Walczak, and M. Swiontek-Brzezinska, "Microbiological and Enzymatic Activity of Soil after Pollution with Fluorine," Polish Journal of Environmental Studies, vol. 24, no. 6, pp. 2641-2646, 2015.

[101] U. Langer and T. Günther, "Effects of alkaline dust deposits from phosphate fertilizer production on microbial biomass and enzyme activities in grassland soils," Environmental Pollution, vol. 112, no. 3, pp. 321-327, 2001.

[102] N. K. Mondal, K. C. Pal, M. Dey, S. Ghosh et al., "Seasonal variation of soil enzymes in areas of fluoride stress in Birbhum District, West Bengal, India," Journal of Taibah University for Science, vol. 9, pp. 133-142, 2015.

[103] F. Vašák, J. Černý, Š. Buráňová, M. Kulhánek, and J. Balík, "Soil pH changes in long-term field experiments with different fertilizing systems," Soil and Water Research, vol. 10, no. 1, pp. 19-23, 2015.

[104] T. Okamaura and T. Matsuhisa, "The fluorine content in favourite foods of Japanese," Japanese Journal of Public Health, vol. 15, no. 14, pp. 41-47, 1967, abstracted in Fluoride, vol. 5, no. 2, 1972.

[105] L. W. Njenga, D. N. Kariuki, and S. M. Ndegwa, "Water-labile fluoride in fresh raw vegetable juices from markets in Nairobi, Kenya," Fluoride, vol. 38, no. 3, pp. 205-208, 2005.

[106] G. Gurusubramanian, A. Rahman, M. Sarmah, S. Ray, and S. Bora, "Pesticide usage pattern in tea ecosystem, their retrospects and alternative measures," Journal of Environmental Biology, vol. 29, no. 6, pp. 813-826, 2008.

[107] K. Chang and C. Atici, "The Food and Agriculture Organization of the United Nations. Implications of Maximum Residue Levels (MRLs) on tea trade," Rome 2015.

[108] "International Standard ISO 3720, Black Tea, Definition and basic requirements," Tech. Rep.

[109] "International Standard ISO 11287-2011 Green Tea-Definition and basic requirements," Tech. Rep.

[110] P. Gluckman and D. Skegg, Health effects of water fluoridation: A review of the scientific evidence. Office of the Prime Ministers Chief Science Advisor, Royal Society of New Zealand, 2014, http://www.pmcsa.org.nz/wp-content/uploads/Health-effectsof-water-fluoridation-Aug2014.pdf.

[111] "Euromonitor International. Tea in New Zealand April 2016," http://www.euromonitor.com/tea-in-new-zealand/report.

[112] "The U.S. Food and Drug Administration (FDA) Regulation 21CFR165.110," http://www.accessdata.fda.gov/scripts/cdrh/ cfdocs/cfcfr/cfrsearch.cfm?fr $=165.110$.

[113] "European Commission Directive 2003/40/EC", https://www .fsai.ie/uploadedFiles/Legislation/Food/LegisationLinks/Water/Directive_2003_40_EC.pdf.

[114] "Foods Standards Australia New Zealand. Fluoride in packaged water. April 2012," https://www.foodstandards.gov.au/code/applications/documents/A1043\%20SD3.pdf. 
[115] "Scientific Opinion on Dietary Reference Values for fluoride," EFSA Journal, vol. 11, no. 8, p. 3332, 2013.

[116] "Water fluoridation for the prevention of dental caries (Review). The Cochrane Library 2015, Issue 6," http://www.cochrane.org/ CD010856/ORAL_water-fluoridation-prevent-tooth-decay.

[117] "Opinion of the Scientific Committee on cosmetic products and non-food products intended for consumers concerning the safety of fluorine compounds in oral hygiene products for children under the age of 6 years. 2003 June; SCCNFP/0653/03: Final," https://ec.europa.eu/health/ph_risk/ committees/04_sccp/docs/sccp_o_024.pdf.

[118] S. M. Adair, W. H. Bowen, B. A. Burtm, J. V. Kumar, S. M. Levy et al., "Recommendations for Using Fluoride to Prevent and Control Dental Caries in the United States, Centers for Disease Control and Prevention, August 17, 2001/50(RR14);1-42," http:// www.cdc.gov/mmwr/preview/mmwrhtmL/rr5014al.htm.

[119] T. Brown, A. Mullee, R. Collings, L. Harvey, L. Hooper et al., "Literature search and review related to specific preparatory work in the establishment of Dietary Reference Values Preparation of an evidence report identifying health outcomes upon which Dietary Reference Values could potentially be based for magnesium, potassium and fluoride," EFSA Supporting Publications, vol. 9, no. 5, 2012, http://www.efsa .europa.eu/sites/default/files/scientific_output/files/main_documents/283e.pdf.

[120] European Food Safety Authority, "Scientific opinion on dietary reference values for fluoride, efsa panel on dietetic products, nutrition, and allergies," EFSA Journal, vol. 11, pp. 3332-3378, 2013.

[121] Institute of Medicine (US) Standing Committee on the Scientific Evaluation of Dietary Reference Intakes. Dietary Reference Intakes for Calcium, Phosphorus, Magnesium, Vitamin D, and Fluoride, Fluoride, National Academies Press (US), Washington, DC, USA, 1997, http://www.ncbi.nlm.nih.gov/books/ NBK109832/.

[122] "European Food Safety Authority (EFSA) Scientific Committee on Food, Tolerable Upper Intake Levels for Vitamins and Minerals," EFSA Journal, 2006.

[123] "Scientific Opinion on principles for deriving and applying Dietary Reference Values," EFSA Panel on Dietetic Products, Nutrition, and Allergies, vol. 8, pp. 1458-1460, 2010.

[124] Directorate General for Health and Consumers, Scientific Committee on Health and Environmental Risks, Critical review of any new evidence on the hazard profile, health effects, and human exposure to fluoride and the fluoridating agents of drinking water, 2010.

[125] "Kiwis HIFF British Habits. The New Zealand Choysa Tea Survey. Marlborough Express, August 2011," http://www.stuff .co.nz/marlborough-express/your-marlborough/competitions/ 5434437/The-Perfect-Kiwi-Cuppa.

[126] Cancer Council NSW, "Cancer Council NSW. Aussie tea drinkers favour the humble mug," https://www.cancercouncil .com.au/media-release/aussie-tea-drinkers-favour-the-humble-mug/.

[127] S. C. Sofuoglu and P. Kavcar, "An exposure and risk assessment for fluoride and trace metals in black tea," Journal of Hazardous Materials, vol. 158, no. 2-3, pp. 392-400, 2008.

[128] R. P. K. Ford, P. J. Schluter, E. A. Mitchell et al., "Heavy caffeine intake in pregnancy and sudden infant death syndrome," Archives of Disease in Childhood, vol. 78, no. 1, pp. 9-13, 1998.

[129] J. E. Hallanger Johnson, A. E. Kearns, P. M. Doran, K. K. Teck, and R. A. Wermers, "Fluoride-related bone disease associated with habitual tea consumption," Mayo Clinic Proceedings, vol. 82, no. 6, pp. 719-724, 2007.

[130] M. P. Whyte, W. G. Totty, V. T. Lim, and G. M. Whitford, "Skeletal fluorosis from instant tea," Journal of Bone and Mineral Research, vol. 23, no. 5, pp. 759-769, 2008.

[131] K. Izuora, J. G. Twombly, G. M. Whitford, J. Demertzis, R. Pacifici et al., "Skeletal Fluorosis from Brewed Tea," The Journal of Clinical Endocrinology \& Metabolism, vol. 96, no. 8, pp. 23182324, 2011.

[132] P. O. Owuor, M. A. Obanda, C. O. Othieno, H. Horita, T. Tsushida, and T. Murai, "Changes in the chemical composition and quality of black tea due to plucking standards," Agricultural and Biological Chemistry, vol. 51, no. 12, pp. 3383-3384, 1987.

[133] P. O. Owuor, A. M. Obanda, T. Tsushida, H. Horita, and T. Murai, "Geographical variation of theaflavins, thearubigins and caffeine in Kenyan clonal black teas," Food Chemistry, vol. 26, no. 3, pp. 223-230, 1987.

[134] P. O. Owuor, J. E. Orchard, J. M. Robinson, and S. J. Taylor, "Variations of the chemical composition of clonal black tea (Camellia sinensis) due to delayed withering," Journal of the Science of Food and Agriculture, vol. 52, no. 1, pp. 55-61, 1990.

[135] P. O. Owuor, C. O. Othieno, H. O. Odhiambo, and W. K. Ng'etich, "Effects of fertiliser levels and plucking intervals on clonal tea (Camellia sinensis (L.O) Kuntze)," Tropical Agriculture, vol. 74, pp. 184-191, 1997.

[136] X. J. Wang, X. Hu, and H. Chen, "Some biogeochemical characteristics of tea soils," Pedosphere, vol. 7, pp. 275-280, 1997.

[137] A. Marcos, A. Fisher, G. Rea, and S. J. Hill, "Preliminary study using trace element concentrations and a chemometrics approach to determine the geographical origin of tea," Journal of Analytical Atomic Spectrometry, vol. 13, no. 6, pp. 521-525, 1998.

[138] K. F. Fung, Z. Q. Zhang, J. W. C. Wong, and M. H. Wong, "Fluoride contents in tea and soil from tea plantations and the release of fluoride into tea liquor during infusion," Environmental Pollution, vol. 104, no. 2, pp. 197-205, 1999.

[139] P. L. Fernández-Cáceres, M. J. Martín, F. Pablos, and A. G. González, "Differentiation of tea (Camellia sinensis) varieties and their geographical origin according to their metal content," Journal of Agricultural and Food Chemistry, vol. 49, no. 10, pp. 4775-4779, 2001.

[140] C. Astill, M. R. Birch, C. Dacombe, P. G. Humphrey et al., "Factors affecting the caffeine and polyphenol contents of black and green tea infusions," Journal of Agricultural and Food Chemistry, vol. 49, no. 11, pp. 5340-5347, 2001.

[141] W. S. Shu, Z. Q. Zhang, C. Y. Lan, and M. H. Wong, "Fluoride and aluminium concentrations of tea plants and tea products from Sichuan Province, PR China," Chemosphere, vol. 52, no. 9, pp. 1474-1482, 2003.

[142] Y. Lu, W.-F. Guo, and X.-Q. Yang, "Fluoride content in tea and its relationship with tea quality," Journal of Agricultural and Food Chemistry, vol. 52, no. 14, pp. 4472-4476, 2004.

[143] Y. Hudaykuliyev, M. Tastekin, E. S. Poyrazoglu, E. Baspinar, and Y. S. Velioglu, "Variables affecting fluoride in Turkish black tea," Fluoride, vol. 38, no. 1, pp. 38-43, 2005.

[144] S. C. Lung, H. Cheng, and C. B. Fu, "Potential exposure and risk of fluoride intakes from tea drinks produced in Taiwan," Journal of Exposure Science and Environmental Epidemiology, vol. 18, no. 2, pp. 158-166, 2007.

[145] O. P. Owuor and B. O. Kwach, "Quality and yields of black tea camellia sinensis L.O. Kuntze in responses to harvesting in Kenya: a review," Asian Journal of Biological and Life Sciences, vol. 1, no. 1, pp. 1-7, 2012. 
[146] H. Gao, Z. Zhang, and X. Wan, "Influences of charcoal and bamboo charcoal amendment on soil-fluoride fractions and bioaccumulation of fluoride in tea plants," Environmental Geochemistry and Health, vol. 34, no. 5, pp. 551-562, 2012.

[147] W. N. Omwoyo, P. O. Owuor, D. M. Ongeri, and D. M. Kamau, "Effect of Genotypes in Different Environments on Micronutrient Content of Black Tea," Journal of Tea Science Research, vol. 4, no. 2, pp. 17-26, 2014.

[148] S. Jabeen, S. Alam, M. Saleem et al., "Withering timings affect the total free amino acids and mineral contents of tea leaves during black tea manufacturing," Arabian Journal of Chemistry, vol. 30, pp. 1-7, 2015

[149] S. Zhao, Y. Liu, J. Ma et al., "Influence of fertilizers on fluoride accumulation in tea leaves and its remediation using polyphenol-Ce adsorbents," RSC Advances, vol. 5, no. 8, pp. 6085-6091, 2015.

[150] J. Yin, Z. Zheng, T. Li et al., "Effect of tea plantation age on the distribution of fluoride and its fractions within soil aggregates in the hilly region of Western Sichuan, China," Journal of Soils and Sediments, vol. 16, no. 8, pp. 2128-2137, 2016.

[151] L. Singer, W. D. Armstrong, and G. T. Vatassery, "Fluoride in commercial tea and related plants," Economic Botany, vol. 21, no. 3, pp. 285-287, 1967.

[152] J. T. Chan and S. H. Koh, "Fluoride content in caffeinated, decaffeinated and herbal teas," Caries Research, vol. 30, no. 1, pp. 88-92, 1996.

[153] Ş. Kalaycı and G. Somer, "Factors affecting the extraction of fluoride from tea: application to three tea samples," Fluoride, vol. 36, no. 4, pp. 267-270, 2003.

[154] G. S. Gao, B. Hou, X. L. Gong, R. H. Tong, and P. Liu, "Influence of different factors on fluorine leaching rate in tea. Southwest China," Southwest China Journal of Agricultural Sciences, vol. 22, pp. 177-181, 2009.

[155] S. C. Ma, X. L. Wang, and Y. R. Liang, "Kinetic study on leaching of fluorine from green tea," African Journal of Pharmacy and Pharmacology, vol. 6, no. 19, pp. 1410-1416, 2012.

[156] A. Maleki, P. Abulmohammadi, P. Teymouri, S. Zandi et al., "Effect of brewing time and water hardness on fluoride release from different Iranian tea," Fluoride, vol. 49, no. 3, pp. 263-273, 2016.

[157] N. Kakumanu and S. D. Rao, "Skeletal fluorosis due to excessive tea drinking," The New England Journal of Medicine, vol. 368, article 1140, 2013.

[158] S. C. Duckworth and R. Duckworth, "The ingestion of fluoride in tea," British Dental Journal, vol. 145, no. 12, pp. 368-370, 1978.

[159] S. H. Wei, F. N. Hattab, and J. R. Mellberg, "Concentration of fluoride and selected other elements in teas," Nutrition, vol. 5, no. 4, pp. 237-240, 1989.

[160] J. Cao, S. F. Luo, J. W. Liu, and Y. Li, "Safety evaluation on fluoride content in black tea," Food Chemistry, vol. 88, no. 2, pp. 233-236, 2004.

[161] J. Cao, J. Liu, Y. Zhao, H. Qu, S. Danzeng et al., "Fluoride in newer tea commodities," Fluoride, vol. 37, no. 4, pp. 296-300, 2004.

[162] A. A. Yam, A. W. Kane, D. Cisse, M. M. Gueye et al., "Traditional tea drinking in senegal: a real source of fluoride intake for the population," Odonto-Stomatologie Tropicale, vol. 87, 1999, http://www.santetropicale.com/Resume/38708.pdf.

[163] Y.-C. Yang, F.-H. Lu, J.-S. Wu, C.-H. Wu, and C.-J. Chang, "The protective effect of habitual tea consumption on hypertension," Archives of Internal Medicine, vol. 164, no. 14, pp. 1534-1540, 2004.
[164] I. A. Hakim, M. A. Alsaif, M. Alduwaihy, K. Al-Rubeaan, A. R. Al-Nuaim, and O. S. Al-Attas, "Tea consumption and the prevalence of coronary heart disease in Saudi adults: Results from a Saudi National Study," Preventive Medicine, vol. 36, no. 1, pp. 64-70, 2003.

[165] T. C. Varun, M. G. Kerutagi, L. B. Kunnal, H. Basavaraja et al., "Consumption pattern of coffee and tea in Karnataka," Journal of Agricultural Science, vol. 22, no. 4, pp. 824-827, 2009.

[166] S. Kuriyama, T. Shimazu, K. Ohmori et al., "Green tea consumption and mortality due to cardiovascular disease, cancer, and all causes in Japan: the Ohsaki study," Journal of the American Medical Association, vol. 296, no. 10, pp. 1255-1265, 2006.

[167] N. Küçer, “The relationship between daily caffeine consumption and withdrawal symptoms: a questionnaire-based study," Turkish Journal of Medical Sciences, vol. 40, no. 1, pp. 105-108, 2010.

[168] A. H. Mahvi, M. A. Zazoli, M. Younecian, and Y. Esfandiari, "Fluoride content of Iranian black tea and tea liquor," Fluoride, vol. 39, no. 4, pp. 266-268, 2006.

[169] M. Ferraroni, A. Tavani, A. Decarli et al., "Reproducibility and validity of coffee and tea consumption in Italy," European Journal of Clinical Nutrition, vol. 58, no. 4, pp. 674-680, 2004.

[170] I. A. Hakim, U. M. Weisgerber, R. B. Harris, D. Balentine, C. A. J. Van-Mierlo, and I. Paetau-Robinson, "Preparation, composition and consumption patterns of tea-based beverages in Arizona," Nutrition Research, vol. 20, no. 12, pp. 1715-1724, 2000.

[171] J. M. Chin, M. L. Merves, B. A. Goldberger, A. Sampson-Cone, and E. J. Cone, "Caffeine content of brewed teas," Journal of Analytical Toxicology, vol. 32, no. 8, pp. 702-704, 2008.

[172] "Overview of Tea (Camellia sinensis) Chain in Argentina. Ministry of Agriculture, Livestock and Fisheries, Argentina. November 2014," http://www.fao.org/fileadmin/templates/est/ meetings/IGGtea21/Presentation-MarketReportArgentina.pdf.

[173] A. Moreda-Piñeiro, A. Fisher, and S. J. Hill, “The classification of tea according to region of origin using pattern recognition techniques and trace metal data," Journal of Food Composition and Analysis, vol. 16, no. 2, pp. 195-211, 2003.

[174] "China rejects tea from Kenya over high fluoride levels. Business Daily, Kenya. April 2015," http://asokoinsight.com/news/chinarejects-tea-from-kenya-over-high-fluoride-levels/.

[175] M. G. Hampton, "Production of black tea," in Tea: Cultivation to Consumption, pp. 459-511, Chapman and Hall, London, UK, 1992.

[176] "Centre for the Promotion of Imports from developing countries (CBI), Product Factsheet, Tea in Ireland, 2014," http:// www.cbi.eu/sites/default/files/study/product-factsheet-tea-ireland-2014.pdf.

[177] S. Kalayci and G. Somer, "Factors affecting the extraction of fluoride from tea: application to three tea samples," Fluoride, vol. 36, pp. 267-270, 2003.

[178] S. Toyota, "Fluorine content in the urine and in the serum of hydrofluoric acid workers as an index of health administration," Sangyo Igaku, vol. 21, no. 4, pp. 335-348, 1979 (Japanese).

[179] L. Chan, Human exposure assessment of fluoride from tea (Camellia Sinensis L.) with specific reference to human bioaccessibility studies [Ph.D. thesis], University of Derby, 2014, http:// derby.openrepository.com/derby/bitstream/10545/325202/6/ Chan\%20\%20Thesis\%20combined\%205-2\%20(2).pdf.

[180] J. Anaise, I. Gedalia, A. Draingel, and V. Westreich, "Fluoride Uptake in Rats Given Nonacidulated and Acidulated Tea," Journal of Dental Research, vol. 53, no. 1, p. 140, 1974. 
[181] J. T. Chan, B. W. Fry, and J. G. Weatherred, "Effect of dietary caffeine on plasma F levels in humans," Journal of Dental Research, pp. 67-188, 1988.

[182] L. K. Massey and S. J. Whiting, "Caffeine, urinary calcium, calcium metabolism and bone," Journal of Nutrition, vol. 123, no. 9, pp. 1611-1614, Sep 1993.

[183] Review of fluoride benefits and risks: report of the Ad Hoc Subcommittee on Fluoride of the Committee to Coordinate Environmental Health and Related Programs. Public Health Service, Dept. of Health and Human Services, 1991.

[184] J. R. Marier, "Some current aspects of environmental fluoride," Science of the Total Environment, vol. 8, pp. 253-265, 1977.

[185] World Health Organization Regional Office for Europe, Air Quality Guidelines for Europe, European Series, No. 91, WHO Regional Publications, 2nd edition, 2000, http://www.euro.who .int/__data/assets/pdf_file/0005/74732/E71922.pdf?ua=1.

[186] J. A. Weatherell, "Fluoride and the Skeletal and Dental Tissues," in Pharmacology of Fluorides, F. A. Smith, Ed., pp. 141-172, Springer-Merlag Inc., New York, NY, USA, 1966.

[187] I. Arnala, E. M. Alhava, and P. Kauranen, "Effects of fluoride on bone in Finland: Histomorphometry of cadaver bone from low and high fluoride areas," Acta Orthopaedica, vol. 56, no. 2, pp. 161-166, 1985.

[188] F. Mostafaei, F. E. McNeill, D. R. Chettle, B. C. Wainman, A. E. Pidruczny, and W. V. Prestwich, "Measurements of fluorine in contemporary urban Canadians: A comparison of the levels found in human bone using in vivo and ex vivo neutron activation analysis," Physiological Measurement, vol. 36, no. 3, pp. 465-487, 2015.

[189] M. A. Boillat, J. Garcia, and L. Velebit, "Radiological criteria of industrial fluorosis," Skeletal Radiology, vol. 5, no. 3, pp. 161-165, 1980.

[190] Y. Wang, Y. Yin, L. A. Gilula, and A. J. Wilson, "Endemic fluorosis of the skeleton: radiographic features in 127 patients," The American Journal of Roentgenology, vol. 162, no. 1, pp. 93-98, 1994.

[191] H.-R. Li, Q.-B. Liu, W.-Y. Wang et al., "Fluoride in drinking water, brick tea infusion and human urine in two counties in Inner Mongolia, China," Journal of Hazardous Materials, vol. 167, no. 1-3, pp. 892-895, 2009.

[192] J. Cao, X. Bai, Y. Zhao, J. Liu, D. Zhou et al., "Fluorosis induced by drinking brick tea," Fluoride, vol. 29, no. 3, pp. 139-142, 1996.

[193] M. Namkaew and P. Wiwatanadate, "Association of fluoride in water for consumption and chronic pain of body parts in residents of San Kamphaeng district, Chiang Mai, Thailand," Tropical Medicine and International Health, vol. 17, no. 9, pp. 1171-1176, 2012.

[194] H. Cook, "Fluoride studies in a patient with arthritis," The Lancet, vol. 298, no. 7728, p. 817, 1971.

[195] B. W. Carnow and S. A. Conibear, "Industrial fluorosis," Fluoride, vol. 14, pp. 172-181, 1981.

[196] X. Ge, Y. Jiang, G. Tang, M. Zhang, and Y. Zhao, "Investigations on the occurrence of osteoarthritis in middle-aged and elderly persons in fluorosis-afflicted regions of Gaomi City with high fluoride concentration in drinking water," Chin Preventive Medicine Tribune, vol. 12, no. 1, pp. 57-58, 2006 (Chinese).

[197] E. Czerwinski, J. Nowak, D. Dabrowska, A. Skolarcnk, B. Kita, and M. Ksiezyk, "Bone and joint pathology in fluoride-exposed workers," Archives of Environmental Health, vol. 43, no. 5, pp. 340-343, 1988.
[198] X. Chen, "Radiological analysis of fluorotic elbow arthritis," Journal of Guiyang Medical College, vol. 13, no. 2, pp. 303-305, 1988 (Chinese).

[199] R. Luo, L. Rui, R. G. Liu, C. Ye, and Z. Z. Guan, "Total knee arthroplasty for the treatment of knee osteoarthritis caused by endemic skeletal fluorosis," Chinese Journal of Tissue Engineering Research, vol. 16, pp. 1555-1557, 2012.

[200] W. Bao, N. Liu, B. Gao, X. Sun, and Q. Deng, "Report of investigations on adult hand osteoarthritis in Fengjiabao Village, Asuo Village, and Qiancheng Village," Chinese Journal of Epidemiology, vol. 22, no. 6, pp. 517-18, 2003.

[201] W. M. Su, R. G. Liu, C. Ye, Y. N. Yu, and Z. Z. Guan, “Total hip arthroplasty for the treatment of severe hip osteoarthritis due to fluorosis," hinese Journal Tissue Engineering Research, vol. 16, no. 9, pp. 1543-1546, 2012.

[202] L. Y. Tartatovskaya, G. N. Samokhvalova, and A. G. Antropov, "Clinical and hygiene assessment of the combined effect on the body of vibration and fluorine," Meditsina Truda i Promyshlennaya Ekologiya, vol. 10, pp. 8-10, 1994.

[203] S. Savas, M. Çetin, M. Akdoğan, and N. Heybeli, "Endemic fluorosis in Turkish patients: Relationship with knee osteoarthritis," Rheumatology International, vol. 21, no. 1, pp. 30-35, 2001.

[204] B. Walitt, M. Pettinger, C. Parks, J. Hunt, B. Howard, and C. Collins, "Coffee and tea consumption and method of coffee preparation in relation to risk of rheumatoid arthritis and systemic lupus erythematosus in postmenopausal womenRheumatic Diseases," Annals of the Rheumatic Diseases, vol. 69, 3, p. 350, 2010.

[205] T. R. Mikuls, J. R. Cerhan, L. A. Criswell, L. Merlino et al., "Coffee, tea, and caffeine consumption and risk of rheumatoid arthritis: results from the Iowa Women's Health Study," Arthritis and Rheumatism, vol. 46, no. 1, pp. 83-91, 2002.

[206] G. Tettamanti, A. Nyman-Iliadou, N. L. Pedersen, R. Bellocco, I. Milsom, and D. Altman, "Influence of smoking, coffee, and tea consumption on bladder pain syndrome in female twins," Urology, vol. 77, no. 6, pp. 1313-1317, 2011.

[207] M. Seferoglu, N. Karli, M. Zarifoglu et al., "Factors for Progression and Chronification of Episodic Migraine: One-year Faceto-face Follow-up Study," Journal of Neurological Sciences, vol. 29, no. 1(30), pp. 1-10, 2012.

[208] Q. Y. Xiang, L. S. Chen, X. D. Chen, C. S. Wang, Y. X. Liang et al., "Serum fluoride and skeletal fluorosis in two villages in Jiangsu Province, China," Fluoride, vol. 38, no. 3, pp. 178-184, 2005.

[209] A. K. Susheela and M. Bhatnagar, "Reversal of fluoride induced cell injury through elimination of fluoride and consumption of diet rich in essential nutrients and antioxidants," Molecular and Cellular Biochemistry, vol. 234-235, pp. 335-340, 2002.

[210] C. V. Harinarayan, N. Kochupillai, S. V. Madhu, N. Gupta, and P. J. Meunier, "Fluorotoxic metabolic bone disease: An osteo-renal syndrome caused by excess fluoride ingestion in the tropics," Bone, vol. 39, no. 4, pp. 907-914, 2006.

[211] T. S. Isbell and R. Villareal-Armamento, "A case of thick but brittle bones and instant tea," Clinical Chemistry, vol. 56, no. 6, pp. 1041-1042, 2010.

[212] K. Izuora, J. G. Twombly, G. M. Whitford, J. Demertzis, R. Pacifici, and M. P. Whyte, "Skeletal fluorosis from brewed tea," Journal of Clinical Endocrinology and Metabolism, vol. 96, no. 8, pp. 2318-2324, 2011.

[213] G. Hayem, M. Ballard, E. Palazzo, N. Somogyi, F. Roux et al., "Insufficiency bone fractures due to fluorosis in heavy tea drinkers," Annals of the Rheumatic Diseases, vol. 63, supplement 1, p. 488, 2004. 
[214] J. Inkovaara, R. Heikinheimo, K. Jarvinen, U. Kasurinen, H. Hanhijarvi, and E. Iisalo, "Prophylactic Fluoride Treatment and Aged Bones," British Medical Journal, vol. 3, no. 5975, pp. 73-74, 1975.

[215] E. S. Kurland, R. C. Schulman, J. E. Zerwekh, W. R. Reinus, D. W. Dempster, and M. P. Whyte, "Recovery from skeletal fluorosis (an enigmatic, American case)," Journal of Bone and Mineral Research, vol. 22, no. 1, pp. 163-170, 2007.

[216] S. Joshi, T. Hlaing, G. M. Whitford, and J. E. Compston, "Skeletal fluorosis due to excessive tea and toothpaste consumption," Osteoporosis International, vol. 22, no. 9, pp. 2557-2560, 2011.

[217] J. Ekstrand, G. Koch, and L. G. Petersson, "Plasma fluoride concentrations in pre-school children after ingestion of fluoride tablets and toothpaste," Caries Research, vol. 17, no. 4, pp. 379384, 1983.

[218] F. V. Zohoori, A. Innerd, L. B. Azevedo, G. M. Whitford, and A. Maguire, "Effect of exercise on fluoride metabolism in adult humans: A pilot study," Scientific Reports, vol. 5, Article ID 16905, 2015.

[219] L. Singer and R. H. Orphaug, "Concentrations of ionic, total and bound fluoride in plasma," Clinical Chemistry, vol. 25, pp. 523$523,1979$.

[220] F. M. Parkins, N. Tinanoff, M. Moutinho, M. B. Anstey, and M. H. Waziri, "Relationships of human plasma fluoride and bone fluoride to age," Calcified Tissue Research, vol. 16, no. 1, pp. 335338, 1974.

[221] R. M. Smiley, E. Ornstein, E. J. Pantuck, C. B. Pantuck, and R. S. Matteo, "Metabolism of desflurane and isoflurane to fluoride ion in surgical patients," Canadian Journal of Anaesthesia, vol. 38, no. 8, pp. 965-968, 1991.

[222] M. Ehrnebo and J. Ekstrand, "Occupational fluoride exposure and plasma fluoride levels in man," International Archives of Occupational and Environmental Health, vol. 58, no. 3, pp. 179190, 1986.

[223] K. A. Krishnamachari, "Skeletal fluorosis in humans: a review of recent progress in the understanding of the disease," Progress in Food \& Nutrition Science, vol. 10, no. 3-4, pp. 279-314, 1986.

[224] P. Roschger, P. Fratzl, S. Schreiber et al., "Bone mineral structure after six years fluoride treatment investigated by backscattered electron imaging (BSEI) and small angle X-ray scattering (SAXS): A case report," Bone, vol. 16, no. 3, p. 407, 1995.

[225] S. Meseg, H. Matzkowski, and V. Hasert, "Fluorosis following the long-term treatment of osteoporosis with sodium fluoride," Zeitschrift fur die Gesamte Innere Medizin und Ihre Grenzgebiete, vol. 41, no. 1, pp. 22-24, 1986 (German).

[226] D. Briancon and P. J. Meunier, "Treatment of osteoporosis with fluoride, calcium and vitamin D," Orthopedic Clinics of North America, vol. 12, pp. 629-648, 1981.

[227] L. R. Brun, S. M. Roma, F. Pérez, and A. Rigalli, "Presencia de inflamación en el tejido óseo de ratas inducida por fluoruro de sodio," Actualizaciones En Osteologia, vol. 8, pp. 19-28, 2012.

[228] M. Kakei, T. Sakae, M. Yoshikawa, and N. Tamura, "Effect of fluoride ions on apatite crystal formation in rat hard tissues," Annals of Anatomy, vol. 189, no. 2, pp. 175-181, 2007.

[229] D. R. Carter and G. S. Beaupré, "Effects of fluoride treatment on bone strength," Journal of Bone and Mineral Research, vol. 5, no. 1S, pp. S177-S184, 1990.

[230] M. Kakei, M. Yoshikawa, and H. Mishima, "Fluoride Exposure May Accelerate the Osteoporotic Change in Postmenopausal Women: Animal Model of Fluoride-induced Osteoporosis," Advanced Techniques in Biology \& Medicine, vol. 04, no. 01, 2015.
[231] E. S. Christenson, X. Jiang, R. Kagan, and P. Schnatz, "Osteoporosis management in post-menopausal women," Minerva Ginecol, vol. 64, no. 3, pp. 181-94, 2012.

[232] E. A. Meagher and G. A. FitzGerald, "Indices of lipid peroxidation in vivo: strengths and limitations," Free Radical Biology and Medicine, vol. 28, no. 12, pp. 1745-1750, 2000.

[233] S. A. Sheweita, K. I. Khoshhal, and H. H. Baghdadi, Osteoporosis and Oxidative Stress-Role of Antioxidants, Systems Biology of Free Radicals and Antioxidants, Springer, Berlin, Germany, 2014.

[234] L. G. Rao and A. V. Rao, Oxidative Stress and Antioxidants in the Risk of Osteoporosis-Role of the Antioxidants Lycopene and Polyphenols, Topics in Osteoporosis, 2013, https://www intechopen.com/books/topics-in-osteoporosis/oxidative-stressand-antioxidants-in-the-risk-of-osteoporosis-role-of-the-antioxidants-lycopene-and-.

[235] B. L. Fina, M. Lombarte, J. P. Rigalli, and A. Rigalli, "Fluoride increases superoxide production and impairs the respiratory chain in ROS 17/2.8 osteoblastic cells," PLoS ONE, vol. 9, no. 6, Article ID e100768, 2014.

[236] S. Podder, A. Chattopadhyay, S. Bhattacharya, M. R. Ray, and A. Chakraborty, "Fluoride-induced genotoxicity in mouse bone marrow cells: Effect of buthionine sulfoximine and N-acetyl- 1cysteine," Journal of Applied Toxicology, vol. 31, no. 7, pp. 618625, 2011.

[237] Q. Chen, Z. Wang, Y. Xiong et al., "Selenium increases expression of HSP70 and antioxidant enzymes to lessen oxidative damage in Fincoal-type fluorosis," Journal of Toxicological Sciences, vol. 34, no. 4, pp. 399-405, 2009.

[238] P. Kalyanalakshmi, M. Vijayabhaskar, and M. Dhananjaya Naidu, "Lipid peroxidation and antioxidant enzyme status of adult males with skeletal fluorosis in Andhra Pradesh, India," Fluoride, vol. 40, no. 1, pp. 42-45, 2007.

[239] A. Dlugosz, A. Roszkowska, and M. Zimmer, "Oestradiol protects against the harmful effects of fluoride more by increasing thiol group levels than scavenging hydroxyl radicals," Basic and Clinical Pharmacology and Toxicology, vol. 105, no. 6, pp. 366373, 2009.

[240] P. Kataraki and P. Rao, "Fluoride and oxidative stress in postmenopausal women," IOSR Journal of Pharmacy (IOSRPHR), vol. 2, no. 5, pp. 57-59, 2012.

[241] K. Ishiguro, "Distribution of fluoride with age in human bone," Journal of Dental Health, vol. 41, no. 5, pp. 607-616, 1991.

[242] P. Kurttio, N. Gustavsson, T. Vartiainen, and J. Pekkanen, "Exposure to natural fluoride in well water and hip fracture: A cohort analysis in Finland," American Journal of Epidemiology, vol. 150, no. 8, pp. 817-824, 1999.

[243] Y. Li, C. Liang, C. W. Slemenda et al., "Effect of long-term exposure to fluoride in drinking water on risks of bone fractures," Journal of Bone and Mineral Research, vol. 16, no. 5, pp. 932-939, 2001.

[244] M. R. Sowers, K. M. Clerk, M. L. Jannausch, and R. B. Wallace, "A prospective study of bone mineral content and fracture in communities with differential fluoride exposure," American Journal of Epidemiology, vol. 133, no. 7, pp. 649-660, 1991.

[245] S. J. Jacobsen, J. Goldberg, T. P. Miles, J. A. Brody, W. Stiers, and A. A. Rimm, "Regional Variation in the Incidence of Hip Fracture: US White Women Aged 65 Years and Older," JAMA: The Journal of the American Medical Association, vol. 264, no. 4, pp. 500-502, 1990.

[246] M. F. R. Sowers, R. B. Wallace, and J. H. Lemke, "The relationship of bone mass and fracture history to fluoride and calcium 
intake: a study of three communities," The American Journal of Clinical Nutrition, pp. 44-889, 1986.

[247] C. Cooper, C. A. C. Wickham, D. J. R. Barker, and S. J. Jacobsen, "Water Fluoridation and Hip Fracture," JAMA: The Journal of the American Medical Association, vol. 266, no. 4, pp. 513-514, 1991.

[248] C. Danielson, J. L. Lyon, M. Egger, and G. K. Goodenough, "Hip Fractures and Fluoridation in Utah's Elderly Population," JAMA: The Journal of the American Medical Association, vol. 268, no. 6, pp. 746-748, 1992.

[249] M. R. Karagas, J. A. Baron, J. A. Barrett, and S. J. Jacobsen, "Patterns of fracture among the United States elderly: Geographic and fluoride effects," Annals of Epidemiology, vol. 6, no. 3, pp. 209-216, 1996.

[250] D. Feskanich, W. Owusu, D. J. Hunter et al., "Use of toenail fluoride levels as an indicator for the risk of hip and forearm fractures in women," Epidemiology, vol. 9, no. 4, pp. 412-416, 1998.

[251] K. R. Phipps, E. S. Orwoll, J. D. Mason, and J. A. Cauley, "Community water fluoridation, bone mineral density, and fractures: prospective study of effects in older women," British Medical Journal, vol. 321, no. 7265, pp. 860-864, 2000.

[252] K. W. Nellans, E. Kowalski, and K. C. Chung, “The Epidemiology of Distal Radius Fractures," Hand Clinics, vol. 28, no. 2, pp. 113-125, 2012.

[253] S. H. Kim, R. M. Szabo, and R. A. Marder, "Epidemiology of humerus fractures in the United States: Nationwide emergency department sample, 2008," Arthritis Care and Research, vol. 64, no. 3, pp. 407-414, 2012.

[254] S. Thangapandiyan and S. Miltonprabu, "Epigallocatechin gallate effectively ameliorates fluoride-induced oxidative stress and DNA damage in the liver of rats," Canadian Journal of Physiology and Pharmacology, vol. 91, no. 7, pp. 528-537, 2013.

[255] M. Serafini, D. Del Rio, D. N. Yao, S. Bettuzzi, and I. Peluso, "Health benefits of tea," in Herbal Medicine: Biomolecular and Clinical Aspects, I. F. F. Benzie and S. Wachtel-Galor, Eds., Chapter 12, CRC Press/Taylor Francis, Boca Raton, Fla, USA, 2nd edition, 2011, https://www.ncbi.nlm.nih.gov/books/NBK92768/.

[256] K. J. Lee and S. H. Lee, "Extraction behavior of caffeine and EGCG from green and black tea," Biotechnology and Bioprocess Engineering, vol. 13, no. 5, pp. 646-649, 2008.

[257] S. Thangapandiyan and S. Miltonprabu, "An in vivo and in vitro studies on the antioxidant property of epigallocatechin gallate on sodium fluoride induced toxicity in rats," International Journal of Phytopharmacology, vol. 4, no. 4, pp. 245-254, 2013.

[258] S. Miltonprabu and S. Thangapandiyan, "Protective effect of epigallocatechin gallate on fluoride-induced oxidative stress related haematotoxicity in rats," Research \& Reviews: Journal of Pharmacology and Toxicological Studies (RRJPTS), vol. 1, no. 2, p. 12, 2013.

[259] S. Thangapandiyan and S. Miltonprabu, "Epigallocatechin gallate supplementation protects against renal injury induced by fluoride intoxication in rats: role of $\mathrm{Nrf} 2 / \mathrm{HO}-1$ signaling," Toxicology Reports, vol. 1, pp. 12-30, 2014.

[260] T. Pandiyan and M. Prabu, "Ameliorative effect of epigallocatechin gallate on sodium fluoride induced oxidative stress mediated metabolism in rat," International Journal of Pharmacology and Toxicology, vol. 2, no. 2, pp. 76-85, 2014.

[261] S. Thangapandiyan and S. M. Prabu, "Epigallocatechin gallate potentially ameliorates sodium fluoride-induced genotoxicity in rats," Asian Journal of Pharmacology and Toxicology, vol. 1, pp. 8-16, 2013.
[262] D. M. Abo El-Khair, F. E. El-Safti,, E. Mostafa M, W. B. ElKholy, and N. M. El-Sherif, "Effect of sodium fluoride on the grey matter of spinal cord in the albino rat and the protective role of green tea extract," Anatomy, vol. 10, no. 2, pp. 114-133, 2016.

[263] S. Thangapandiyan and S. Miltonprabu, "Epigallocatechin gallate exacerbates fluoride-induced oxidative stress mediated testicular toxicity in rats through the activation of Nrf2 signaling pathway," Asian Pacific Journal of Reproduction, vol. 4, no. 4, article no. 20, pp. 272-287, 2015.

[264] S. Miltonprabu and S. Thangapandiyan, "Epigallocatechin gallate potentially attenuates Fluoride induced oxidative stress mediated cardiotoxicity and dyslipidemia in rats," Journal of Trace Elements in Medicine and Biology, vol. 29, pp. 321-335, 2015.

[265] T. Shanmugam, M. Selvaraj, and S. Poomalai, "Epigallocatechin gallate potentially abrogates fluoride induced lung oxidative stress, inflammation via Nrf2/Keap1 signaling pathway in rats: An in-vivo and in-silico study," International Immunopharmacology, vol. 39, pp. 128-139, 2016.

[266] S. Thangapandiyan and S. Miltonprabu, "Epigallocatechin gallate protects against oxidative stress-mediated neurotoxicity and hippocampus dysfunction induced by fluoride in rats," International Journal of Medical Health Sciences, vol. 2, no. 12, 2015.

[267] S. T. Pandiyan and S. M. Prabu, Epigallocatechin Gallate Protects Fluoride Induced Neurotoxicity, Lambert Academic Publishing, 2016.

[268] P. Carloni, L. Tiano, L. Padella et al., "Antioxidant activity of white, green and black tea obtained from the same tea cultivar," Food Research International, vol. 53, no. 2, pp. 900-908, 2013.

[269] M. Serafini, A. Ghiselli, and A. Ferro-Luzzi, "In vivo antioxidant effect of green and black tea in man," European Journal of Clinical Nutrition, vol. 50, no. 1, pp. 28-32, 1996.

[270] S. C. Langley-Evans, "Consumption of black tea elicits an increase in plasma antioxidant potential in humans," International Journal of Food Sciences and Nutrition, vol. 51, no. 5, pp. 309-315, 2000.

[271] L. Ryan and S. Petit, "Addition of whole, semiskimmed, and skimmed bovine milk reduces the total antioxidant capacity of black tea," Nutrition Research, vol. 30, no. 1, pp. 14-20, 2010.

[272] M. W. Korir, F. N. Wachira, J. K. Wanyoko, R. M. Ngure, and R. Khalid, "The fortification of tea with sweeteners and milk and its effect on in vitro antioxidant potential of tea product and glutathione levels in an animal model," Food Chemistry, vol. 145, pp. 145-153, 2014.

[273] R. J. Green, A. S. Murphy, B. Schulz, B. A. Watkins, and M. G. Ferruzzi, "Common tea formulations modulate in vitro digestive recovery of green tea catechins," Molecular Nutrition and Food Research, vol. 51, no. 9, pp. 1152-1162, 2007.

[274] D. Komes, D. Horžić, A. Belščak, K. K. Ganić, and I. Vulić, "Green tea preparation and its influence on the content of bioactive compounds," Food Research International, vol. 43, no. 1, pp. 167-176, 2010.

[275] T. Kaur, R. K. Bijarnia, and B. Nehru, "Effect of concurrent chronic exposure of fluoride and aluminum on rat brain," Drug and Chemical Toxicology, vol. 32, no. 3, pp. 215-221, 2009.

[276] T. H. Ittel, E. Gruber, A. Heinrichs, S. Handt, F. Hofstadter, and H.-G. Sieberth, "Effect of fluoride on aluminum-induced bone disease in rats with renal failure," Kidney International, vol. 41, no. 5, pp. 1340-1348, 1992. 
[277] R. Raina, N. A. Baba, P. K. Verma, M. Sultana, and M. Singh, "Hepatotoxicity induced by subchronic exposure of fluoride and chlorpyrifos in Wistar rats: Mitigating effect of ascorbic acid," Biological Trace Element Research, vol. 166, no. 2, pp. 157162, 2015.

[278] N. A. Baba, R. Raina, P. K. Verma, M. Sultana, S. Prawez, and N. A. Nisar, "Toxic effects of fluoride and chlorpyrifos on antioxidant parameters in rats: protective effects of vitamins $\mathrm{C}$ and E," Fluoride, vol. 46, no. 2, pp. 73-79, 2013.

[279] N. Dubey, R. Raina, and A. M. Khan, "Toxic effects of deltamethrin and fluoride on antioxidant parameters in rats," Fluoride, vol. 45, no. 3, pp. 242-246, 2012.

[280] N. Dubey, A. M. Khan, and R. Raina, "Sub-acute deltamethrin and fluoride toxicity induced hepatic oxidative stress and biochemical alterations in rats," Bulletin of Environmental Contamination and Toxicology, vol. 91, no. 3, pp. 334-338, 2013.

[281] Institute of Environmental Science \& Research, "Research, Estimated Dietary fluoride intakes for New Zealanders," 2009.

[282] Review of Fluoride, Benefits and risks. Public Health Service, Department of Health and Human Services, February 1991, https://health.gov/environment/Reviewoffluoride/.

[283] Statistics New Zealand, “Tobacco Smoking 2014/2015,” http:// www.stats.govt.nz/browse_for_stats/snapshots-of-nz/nz-socialindicators/Home/Health/tobacco-smoking.aspx.

[284] A. Jain, B. K. Agrawal, M. Varma, and A. A. Jadhav, "Antioxidant status and smoking habits: Relationship with diet," Singapore Medical Journal, vol. 50, no. 6, pp. 624-627, 2009.

[285] T. Okamura and T. Matsuhise, "The content of fluorine in cigarettes," Journal of the Food Hygienic Society of Japan, vol. 6, pp. 382-385, 1965.

[286] A. K. Yadav, C. P. Kaushik, A. K. Haritash, B. Singh, S. P. Raghuvanshi, and A. Kansal, "Determination of exposure and probable ingestion of fluoride through tea, toothpaste, tobacco and pan masala," Journal of Hazardous Materials, vol. 142, no. 1-2, pp. 77-80, 2007.

[287] "Report by Access Economics Pty Limited for: Arthritis New Zealand. The economic cost of Arthritis in New Zealand in 2010," 2016, http://www.arthritis.org.nz/wp-content/uploads/ 2011/07/economic-cost-of-arthritis-in-new-zealand-final-print .pdf.

[288] Ministry of Health, "Annual Update of Key Results 2014/15: New Zealand Health Survey. Wellington: Ministry of Health," 2015, http://www.health.govt.nz/system/files/documents/publications/annual-update-key-results-2014-15-nzhs-dec15-1.pdf.

[289] N. Swain and M. Johnson, "Chronic pain in New Zealand: a community sample," The New Zealand Medical Journal, vol. 127, no. 1388, pp. 21-30, 2014.

[290] C. Dominick, F. Blyth, and M. Nicholas, "Patterns of chronic pain in the New Zealand population," The New Zealand Medical Journal, vol. 124, no. 1337, pp. 63-76, 2011.

[291] J. Wu, W. Wang, Y. Liu et al., "Modifying role of GSTP1 polymorphism on the association between tea fluoride exposure and the brick-tea type fluorosis," PLoS ONE, vol. 10, no. 6, Article ID e0128280, 2015.

[292] J. Tu, K. Liu, Y. Song, Y. Zhang, C. Cui, and C. Lu, "Interactive effect of fluoride burden with calcitonin receptor gene polymorphisms on the risk of $\mathrm{F}$ bone injury," International Archives of Occupational and Environmental Health, vol. 84, no. 5, pp. 533538, 2011.

[293] M. Jiang, L. Mu, Y. Wang, W. Yan, and Y. Jiao, “The relationship between Alu i polymorphisms in the calcitonin receptor gene and fluorosis endemic to Chongqing, China," Medical Principles and Practice, vol. 24, no. 1, pp. 80-83, 2015.

[294] M. Dehghan, R. Pourahmad-Jaktaji, and Z. Farzaneh, "Calcitonin receptor AluI (rs1801197) and TaqI calcitonin genes polymorphism in 45-and over 45-year-old women and their association with bone density," Acta Informatica Medica, vol. 24, no. 4, pp. 239-243, 2016.

[295] A. N. Thomson, G. E. White, and R. West, "The prevalence of bad headaches including migraine in a multiethnic community," The New Zealand Medical Journal, vol. 106, no. 967, pp. 477-480, 1993.

[296] P. Brown, R. McNeill, E. Radwan, and J. Willingale, "he Burden of Osteoporosis in New Zealand: 2007-2020. Centre for Health Services Research and Policy," October 2007, https://www .iofbonehealth.org/sites/default/files/PDFs/white_paper_new_ zealand_2007.pdf.

[297] K. J. Coppell, J. I. Mann, S. M. Williams, E. Jo, and P. L. Drury, "Prevalence of diagnosed and undiagnosed diabetes and prediabetes in New Zealand: findings from the 2008/09 Adult Nutrition Survey," The New Zealand Medical Journal, vol. 126, no. 1370, pp. 23-42, 2013.

[298] C. Thomas and L. Thomas, "Renal failure-measuring the glomerular filtration rate," Deutsches Ärzteblatt International, vol. 106, no. 51-52, pp. 849-854, 2009.

[299] W. K. Seow and M. J. Thomsett, "Dental fluorosis as a complication of hereditary diabetes insipidus: studies of six affected patients," Pediatric Dentistry, vol. 16, no. 2, pp. 128-132, 1994.

[300] M. Torra, M. Rodamilans, and J. Corbella, "Serum and urine fluoride concentration: Relationships to age, sex and renal function in a non-fluoridated population," Science of the Total Environment, vol. 220, no. 1, pp. 81-85, 1998.

[301] J. S. Al-Wakeel, A. H. Mitwalli, S. Huraib et al., "Serum ionic fluoride levels in haemodialysis and continuous ambulatory peritoneal dialysis patients," Nephrology Dialysis Transplantation, vol. 12, no. 7, pp. 1420-1424, 1997.

[302] T. Kimura, T. Ando, G. Yamamotq, and K. Yoshitake, "Ionic and Nonionic Fluoride Levels in Blood of Dialyzed and Undialyzed Patients with Renal Failure and Kidney Transplanted Patients," Japanese Journal of Medical Science and Biology, vol. 46, no. 3, pp. 131-139, 1993.

[303] R. D. Lindeman, J. Tobin, and N. W. Shock, "Longitudinal studies on the rate of decline in renal function with age," Journal of the American Geriatrics Society, vol. 33, no. 4, pp. 278-285, 1985.

[304] J. R. Weinstein and S. Anderson, "The aging kidney: physiological changes," Advances in Chronic Kidney Disease, vol. 17, no. 4, pp. 302-307, 2010.

[305] Toxicological Profile For Fluorides, Hydrogen Fluoride, And Fluorine. U.S. Department of Health and Human Services, U.S. Public Health Service, Agency for Toxic Substances and Disease Registry. April 1993.

[306] G. Thornton, "Aged residential care service review: Grant Thornton," 2010, http://nzaca.org.nz/assets/Documents/ARSCR-FullReport.pdf.

[307] S. A. Skeaff, C. D. Thomson, N. Wilson, and W. R. Parnell, "A comprehensive assessment of urinary iodine concentration and thyroid hormones in New Zealand schoolchildren: a crosssectional study," Nutrition Journal, vol. 11, no. 1, article 31, 2012.

[308] J. C. Edmonds, R. M. McLean, S. M. Williams, and S. A. Skeaff, "Urinary iodine concentration of New Zealand adults improves with mandatory fortification of bread with iodised salt but not 
to predicted levels," European Journal of Nutrition, vol. 55, no. 3, pp. 1201-1212, 2016.

[309] J. C. Miller, S. O. MacDonell, A. R. Gray et al., "Iodine status of New Zealand elderly residents in long-term residential care," Nutrients, vol. 8, no. 8, article no. 445, 2016.

[310] R. Pan, H.-P. Chen, M.-L. Zhang, Q.-H. Wang, Y. Jiang, and X. Liu, "Dissipation pattern, processing factors, and safety evaluation for dimethoate and its metabolite (omethoate) in tea (Camellia sinensis)," PLoS ONE, vol. 10, no. 9, Article ID e0138309, 2015.

[311] A. Bishnu, K. Chakrabarti, A. Chakraborty, and T. Saha, "Pesticide residue level in tea ecosystems of Hill and Dooars regions of West Bengal, India," Environmental Monitoring and Assessment, vol. 149, no. 1-4, pp. 457-464, 2009.

[312] J. M. Colina, C. F. Arias, and A. Rodriguez, "The influence of the composition of the TISAB solution on the determination of fluoride in tea infusions," Fluoride - Quarterly Reports, vol. 23, no. 1, pp. 20-26, 1990.

[313] J. Janiszewska and M. Balcerzak, "Analytical Problems with the Evaluation of Human Exposure to Fluorides from Tea Products," Food Analytical Methods, vol. 6, no. 4, pp. 1090-1098, 2013. 


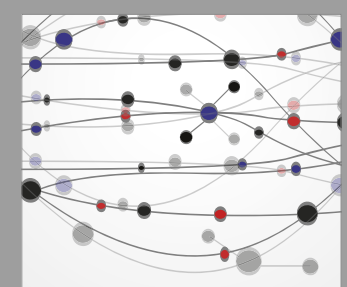

The Scientific World Journal
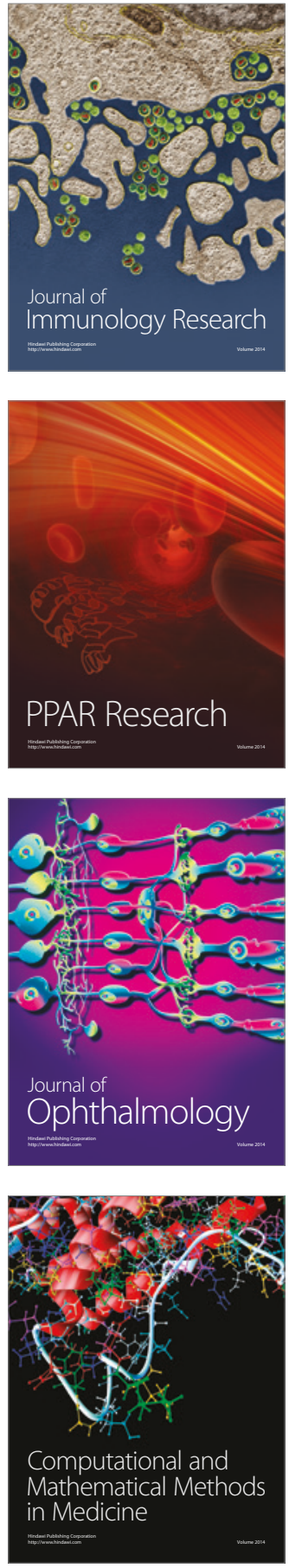

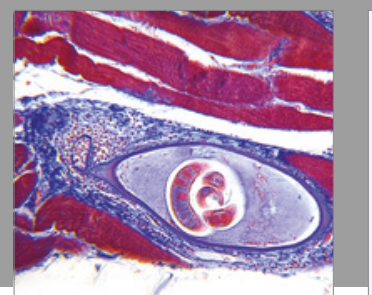

Gastroenterology Research and Practice
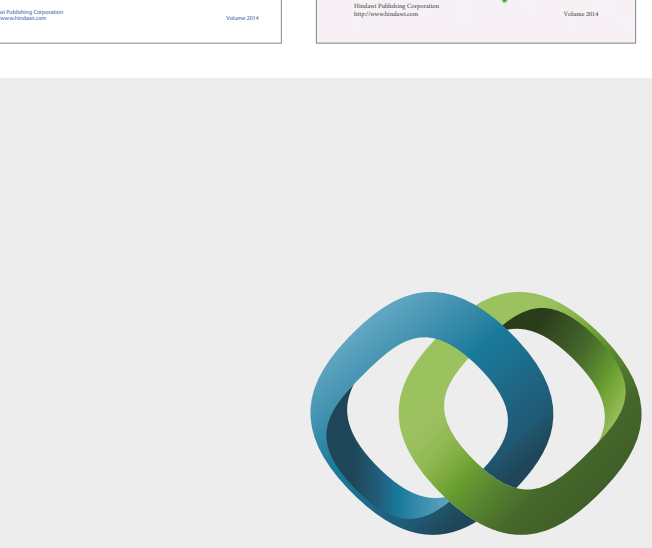

\section{Hindawi}

Submit your manuscripts at

https://www.hindawi.com
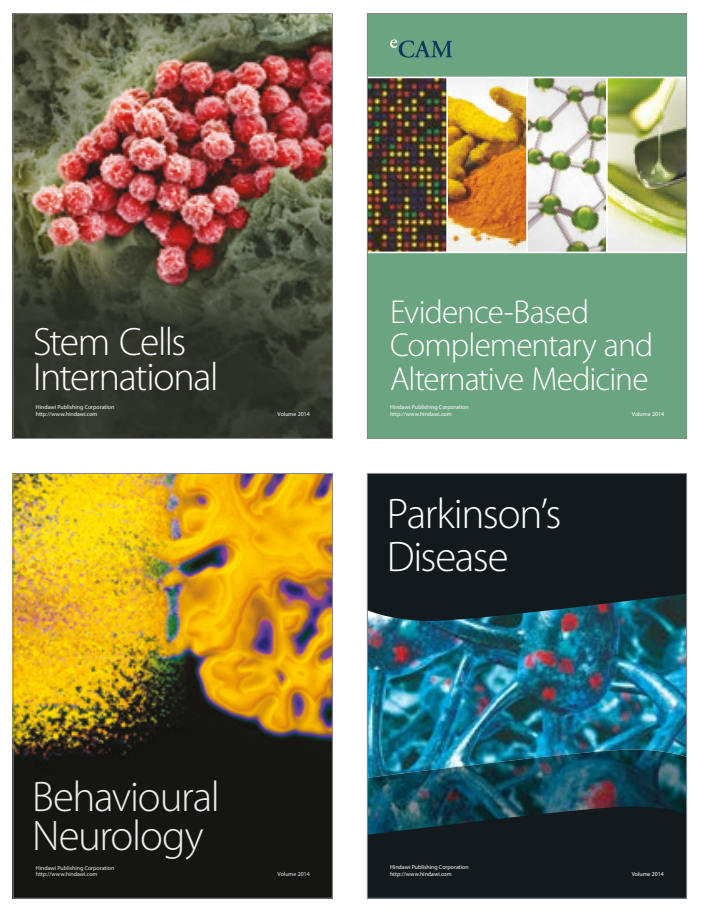
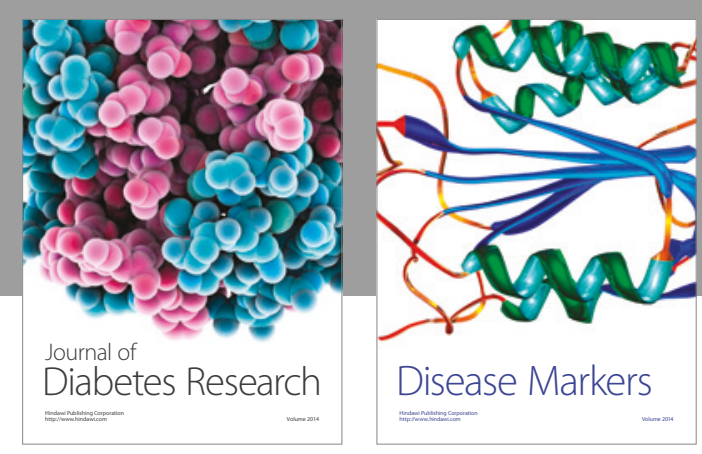

Disease Markers
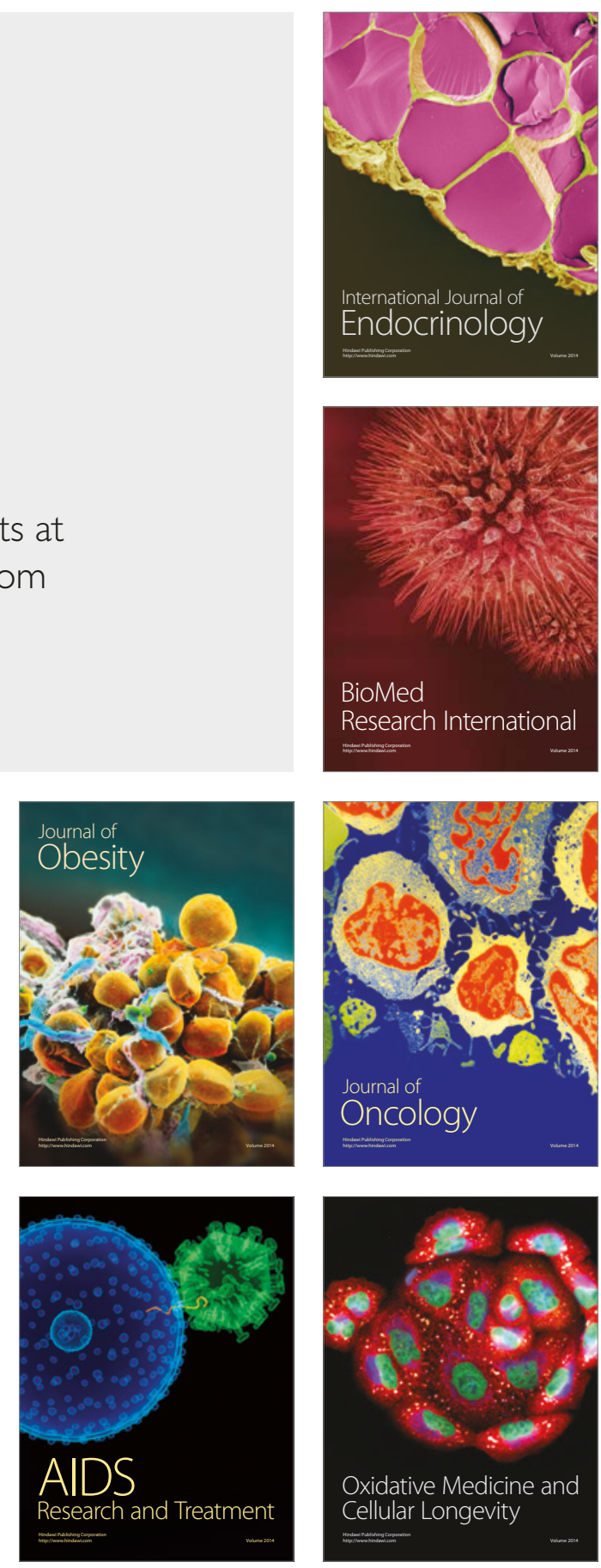